\title{
Understanding autism and other neurodevelopmental disorders through experimental translational neurobehavioral models
}

\author{
Judith R. Homberg ${ }^{1 *}$, Evan J. Kyzar ${ }^{2,3^{*}}$, Michael Nguyen ${ }^{3,4}$, William H. Norton ${ }^{5}$, Julian Pittman ${ }^{6}$, \\ Manoj K. Poudel ${ }^{3}$, Siddharth Gaikwad ${ }^{3}$, Shun Nakamura ${ }^{7}$, Mamiko Koshiba ${ }^{8}$, Hideo Yamanouchi ${ }^{8}$, \\ Maria Luisa Scattoni ${ }^{9}$, Jeremy F.P. Ullman ${ }^{10}$, David M. Diamond ${ }^{11,12}$, Aleksandra A. Kaluyeva ${ }^{3}$, \\ Matthew O. Parker ${ }^{13}$, Victor M. Klimenko ${ }^{14}$, Sergey A. Apryatin ${ }^{15}$, Richard E. Brown ${ }^{16}$, \\ Cai Song ${ }^{16,17,18}$, Raul R. Gainetdinov ${ }^{19,20}$, Irving I. Gottesman ${ }^{21}$ and Allan V. Kalueff $f^{17,19,22^{* *}}$
}

${ }^{1}$ Department of Cognitive Neuroscience, Donders Institute for Brain, Cognition, and Behaviour, Radboud University Medical Centre, Nijmegen, Netherlands

${ }^{2}$ Department of Psychiatry, College of Medicine, University of Illinois at Chicago, Chicago, IL, USA

${ }^{3}$ The International Stress and Behavior Society (ISBS) and ZENEREI Research Center, Slidell, LA, USA

${ }^{4}$ New York University School of Medicine, New York, NY, USA

${ }^{5}$ Department of Biology, University of Leicester, Leicester, UK

${ }^{6}$ Department of Biological and Environmental Sciences, Troy University, Troy, AL, USA

${ }^{7}$ Tokyo University of Agriculture and Technology, Tokyo, Japan

${ }^{8}$ Departments of Pediatrics and Biochemistry, Saitama Medical University, Saitama, Japan

${ }^{9}$ Department of Cell Biology and Neurosciences, Istituto Superiore di Sanita, Rome, Italy

${ }^{10}$ Centre for Advanced Imaging, University of Queensland, Brisbane, Queensland, Australia

${ }^{11}$ Department of Psychology, University of South Florida, Tampa, FL, USA 
${ }^{12}$ J.A. Haley Veterans Hospital, Research and Development Service, Tampa, FL, USA

${ }^{13}$ School of Health Sciences and Social Work, University of Portsmouth, Portsmouth, UK

${ }^{14}$ Pavlov Physiology Department, Institute of Experimental Medicine IEM RAS, St. Petersburg,

Russia

${ }^{15}$ Research Institute of Nutrition RAS, Moscow, Russia

${ }^{16}$ Department of Psychology and Neuroscience, Dalhousie University, Halifax, Nova Scotia, Canada

${ }^{17}$ Research Institute of Marine Drugs and Nutrition, College of Food Science and Technology, Guangdong Ocean University, Zhanjiang, Guangdong, China

${ }^{18}$ Graduate Neuroscience Institute, China Medical University Hospital, Taichung, Taiwan

${ }^{19}$ Institute of Translational Biomedicine, St. Petersburg State University, St. Petersburg, Russia

${ }^{20}$ Skolkovo Institute of Science and Technology, Skolkovo, Moscow Region, Russia

${ }^{21}$ Department of Psychology, University of Minnesota, Minneapolis, MN, USA

${ }^{22}$ Institutes of Chemical Technology and Natural Sciences, Ural Federal University, Ekaterinburg, Russia

*These authors equally contributed to this study

\section{**Corresponding Author:}

Allan V. Kalueff, PhD

Research Institute of Marine Drugs and Nutrition, College of Food Science and Technology, Guangdong Ocean University, Zhanjiang, Guangdong, China

Tel/Fax.: +1-240-328-2275

Email: avkalueff@gmail.com 


\begin{abstract}
Neurodevelopmental disorders (NDDs) are highly prevalent and severely debilitating brain illnesses caused by aberrant brain growth and development. Resulting in cognitive, social, motor, language and affective disabilities, common NDDs include autism spectrum disorder (ASD), intellectual disability, communication/speech disorders, motor/tic disorders and attention deficit hyperactivity disorder. Affecting neurogenesis, glia/neuronal proliferation and migration, synapse formation and myelination, aberrant neural development occurs over a substantial period of time. Genetic, epigenetic, and environmental factors play a key role in NDD pathogenesis. Animal models are an indispensable tool to study NDDs. Paralleling clinical findings, we comprehensively evaluate various preclinical tests and models which target key (social, cognitive, motor) neurobehavioral domains of ASD and other common NDDs. Covering both traditional (rodent) and alternative NDD models, we outline the emerging areas of research and emphasize how preclinical models play a key role in gaining translational and mechanistic insights into NDDs and their therapy.
\end{abstract}

Keywords: neurodevelopmental disorder, model organism, experimental model, preclinical study, translational research 


\section{Research highlights:}

- Neurodevelopmental disorders are common and widespread psychiatric illnesses

- Autism and other neurodevelopmental deficits often occur in early development

- Animal models are a valuable tool to study autism and other neurodevelopmental disorders

- We parallel clinical and preclinical data to gain a translational perspective of these illnesses 


\section{Introduction}

Neurodevelopmental disorders (NDDs) represent clinically heterogeneous, heritable psychiatric illnesses caused by aberrant brain growth and development (American Psychiatric et al., 2013; Hansen et al., 2013; Homberg et al., 2015). Presenting with motor, cognitive, language and affective disabilities, common NDDs include autism spectrum disorder (ASD), social communication disorders, intellectual disability (ID), attention deficit hyperactivity (ADHD) and motor/tic disorders (Table 1, Fig. 1) (American Psychiatric et al., 2013; Hansen et al., 2013). While NDD symptoms typically emerge during childhood, aberrant neural development usually starts during early embryogenesis (Hu et al., 2014; Sadler, 2006) and continues over a substantial period of time. Affecting neurogenesis, glia/neuronal proliferation and migration, synapse formation and myelination (Fig. 1) (Ding, 2015; Frederick and Stanwood, 2009; Hu et al., 2014; Rice and Barone, 2000), these developmental changes lead to long-lasting behavioral and physiological deficits in both child- and adulthood (Bergner et al., 2010; Buckley et al., 2009; Krishnan, 2005). Depending on the brain structure(s) or the stage of neural development affected, clinical manifestations of NDDs range from specific symptoms to global mental impairments (Table 1) (American Psychiatric et al., 2013; Hansen et al., 2013). In addition, NDDs frequently co-occur (e.g., ADHD with learning disability, ASD with ID) and overlap with other brain disorders, forming a complex spectrum of neuropsychiatric comorbidities (Fig. 1) (Bergner et al., 2010; Buckley et al., 2009; Krishnan, 2005)

NDDs remain a relatively unmet biomedical concern (Bergner et al., 2010; Buckley et al., 2009; Krishnan, 2005) with high prevalence and socio-economic impact (Dykens, 2015). In addition, NDDs cause significant distress and persistent impairments of behavior, memory/learning, social communication, occupational performance and other important daily activities (American Psychiatric et al., 2013; Hansen et al., 2013). Multiple therapeutic approaches to NDDs include pharmacotherapy, behavioral therapy and rehabilitation, such as physical or speech/language therapy (Hansen et al., 2013). However, specific and effective treatments for NDDs are lacking, as we do not know the 
biological targets and the exact symptoms, which are also often detected at clinically advanced stages, past the best therapeutic intervention period (Homberg et al., 2015). This, as well as the growing health burden of NDDs (Fig. 2), necessitate further translational research in this field and the development of valid preclinical models, novel biomarkers and therapies.

To address these challenges, the International Stress and Behavior Society (ISBS) has established the Strategic Task Force on NDDs - a team of international experts representing different clinical and preclinical fields (Homberg et al., 2015). Complementing the Panel's recommendations on improving pharmacotherapy of NDDs (Homberg et al., 2015), the present review parallels clinical symptoms of ASD and several other common NDDs with their existing preclinical paradigms, and evaluates various tests and models of animal neurobehavioral development, social behaviors, restricted interests and behavioral perseverations. Covering both traditional (rodent) and alternative models of NDDs, we outline the emerging areas of research and emphasize how preclinical models help gain translational and mechanistic insights into NDDs and their therapy.

\section{Animals models of neurodevelopmental disorders}

Since a key function of the nervous system is to produce behavior, behavioral analyses provide the most meaningful assessment of the central nervous system (CNS) and its deficits. For example, rodent tests are commonly used to measure neural phenotypes in behavioral genetics, developmental psychobiology, psychopharmacology and neurotoxicology (Buelke-Sam and Kimmel, 1979; Butcher, 1976; Elmazar and Sullivan, 1981; Reiter, 1978; Vorhees et al., 1979). However, because of multiple limitations inherent in experimental modeling of complex human brain disorders (Cachat et al., 2011; Kalueff and Tuohimaa, 2005b; Kalueff et al., 2007e), targeting the entire spectrum of clinical NDDs is impossible (Table 1). Nevertheless, animal paradigms continue to be indispensable for studying the neurobiology of human NDDs (Kalueff et al., 2007e). In general, a good animal model should possess three main attributes: construct validity (conforming to the underlying rationale of the disease), face validity (mimicking some of the characteristics of the 
disease) and predictive validity (allowing the prediction of novel disease symptoms, or identification of disease treatments) (Kalueff et al., 2007e; Stewart and Kalueff, 2015). The animal model should also combine genetic tractability, tools to visualize and manipulate neurons in vivo, and the ability to translate findings to patients based upon conserved neurobiology. Two major groups of preclinical paradigms merit discussion here. One group is behavioral tests which assess NDD-linked phenotypes, and therefore often have high face and predictive validity. The second group represents experimental models relevant to NDD pathogenesis (Fig. 2), and therefore possesses high construct validity. Both types of preclinical paradigms can be used complementarily to gain translational and mechanistic insights into NDD pathogenesis (Table 2).

\subsection{Tests of rodent neurobehavioral development}

Numerous tests for neurobehavioral development in young rodents can be organized into five broad behavioral domains: simple reflexes, sensory function, motor function/coordination, learning/memory and emotionality (Table 3). Simple reflex tests measure behavioral responses that are relatively simple in form, resistant to motivational influences, and often mediated by a small number of sensory and motor neurons. The appearance or disappearance of reflexes from birth is used to assess the rate of maturation of the CNS and differences in the day of appearance or disappearance of reflexes may be used as predictors for NDDs. Tests used to measure sensory development and reactivity assess a wide range of different (e.g., visual, vestibular, auditory and olfactory) systems (Table 3). Differences or abnormalities in rate of sensory development may be indicative of abnormal neuronal pathways associated with NDDs. Furthermore, tests used to assess locomotor activity reflect both exploratory behavior and a state of arousal or "nonspecific excitability" in the context of motor function (Table 3). Proper development of motor coordination can be assessed using numerous tests, such as rotarod and gait analysis, which provide spatial and temporal characteristics of limb movement during locomotion. 
Addressing another critical (cognitive) domain, Table 3 outlines learning and memory tests suitable for young rodents, whose immature sensory and motor systems place limitations on their ability to perform certain tasks or express certain learned associations. These tests have been used to assess such aspects of learning and memory as habituation, avoidance, retention, conditioning, and spatial, delayed, discrimination, and reversal learning. Finally, emotionality represents a key neurobehavioral domain often affected during neural development in both animal and clinical studies (Homberg et al., 2015). In general, assessing emotionality in rodents is a difficult task. Four issues are of particular importance to consider: how to measure emotions directly, how to classify emotional states, how to attribute overt behavior to covert emotional states, and how to identify animal models that are good models of human emotional reactions. Several robust tests of emotionality are summarized in Table 3 and have been recently comprehensively evaluated elsewhere (Cryan and Holmes, 2005; Griebel and Holmes, 2013), including altered emotionality in several rodent models of NDDs (Bolivar and Brown, 1994; Branchi and Ricceri, 2002; Martinez-Cue et al., 2006; Ricceri et al., 2007).

\subsection{Rodent tests of social behaviors}

Social deficits are a common symptom of ASD and many other NDDs. Popular rodent behavioral assays designed to target social behaviors characterize social interaction and communication deficits (Bishop and Lahvis, 2011; Crawley, 2004, 2007; Hunsaker, 2012; Lahvis and Black, 2011; Silverman et al., 2010b). Rodents are particularly suitable to model NDD-associated social deficits since both mice and rats are highly social species with a wide repertoire of social behaviors, including parenting, communal nesting and juvenile play as well as sexual and aggressive behaviors as adults. One of the most popular paradigms, the social interaction test evaluates social responses of the subject mouse directly facing a co-specific (i.e., a freely moving stimulus mouse). Importantly, this also allows a concomitant measurement of ultrasonic vocalizations (USVs) to simultaneously assess rodent social and vocal repertoires. During the social interaction test, mice 
typically investigate each other by sniffing (of anogenital regions, heads or the rest of the body), by crawling over/under each other and/or by reciprocal following. This test is easy to perform, and can utilize either same-sex or mixed pairs. Moreover, in both the male-female and female-female social interaction tests, emission of USVs $(40-80 \mathrm{kHz})$ is a consistent robust phenomenon, considered an index of social interest and motivation (Moles et al., 2007; Nyby, 2001; Scattoni et al., 2009). USVs positively correlate with social investigation, such as anogenital sniffing (Moles et al., 2007; Nyby, 1983; Sales, 1972; Scattoni et al., 2011). Digital spectrographic analysis enables the collection of further information on USVs (e.g., waveforms of the calls), classified into several categories based on internal frequency, duration and spectrographic shape (Ey et al., 2013; Roy et al., 2012; Scattoni et al., 2008; Scattoni et al., 2011; Tyzio et al., 2014). Importantly, since mice engage in social interaction as juveniles, these tests are suitable for studying developmental trajectories of social behaviors, which is relevant to modeling NDDs in general.

In behavioral studies, mouse preference for a social (vs. non-social) context, as well their ability to recognize an unfamiliar co-specific (social recognition), are important traits. The social approach task evaluates these two social aspects at two different test phases in the same apparatus (Moy et al., 2004; Nadler et al., 2004; Yang et al., 2011). This test has become extremely popular in phenotyping of ASD mouse models, since it is unbiased to individual variations in behavior of a social stimulus (a stranger mouse confined under small wire cages); is less time-consuming than other related tests (Pearson et al., 2012); can be used in an automated manner; and because mice can be tested at different ages (an opportunity scarcely exploited so far), thus offering the possibility to follow developmental trajectories. However, since the stimulus mouse is contained under a wire cup, the three-chamber social approach apparatus only measures social approach initiated by the subject mouse (also note that the strain of both stimulus and testing mouse can influence the results, and therefore must be carefully considered). This permits the olfactory, auditory and visual contact, avoids sexual and aggressive behaviors, but also prevents a fine-grain evaluation of the social 
behaviors and their reciprocity. As already mentioned, various other disorders, both within (e.g., ADHD) and beyond NDD spectrum (e.g., schizophrenia, depression, anxiety), present with social deficits, and a careful dissection of these factors in respective animal assays is necessary. Thus, it is useful to combine the social approach with the social interaction tests (Feyder et al., 2010; Jamain et al., 2008; Peca J et al., 2011; Radyushkin et al., 2009; Schmeisser et al., 2012), as well as to apply tests assessing other behavioral domains (e.g., activity, memory, affect), for a more accurate characterization of rodent social deficits.

Since NDDs typically have an early onset, behavioral phenotyping targeting the early developmental period is crucial (Bale et al., 2010; Branchi and Ricceri, 2002), although aberrant phenotypes can be present at different developmental stages. For instance, USVs, emitted by mouse pups in response to separation from mother and littermates, are considered a reliable index of pup social motivation (Branchi et al., 2010; Ehret, 2005; Sewell, 1970), suitable for the identification of early communication deficits in ASD mouse models (Wohr and Scattoni, 2013). Pup isolationinduced USVs can reflect aversive affective states, eliciting maternal exploratory and retrieval behaviors (Knutson et al., 2002; Panksepp, 2003; Zippelius and Schleidt, 1956). Usually pups vocalize for a brief period after separation from the nest, and then rapidly habituate. During early postnatal days, USVs follow a clear strain-dependent ontogenetic profile, with a typical peak around Days 5-8, and a progressive decrease afterwards (Elwood and Keeling, 1982; Hahn et al., 1998; Roubertoux et al., 1996). Unusual calling patterns and reduced vocalization rates, sometimes associated with a restricted vocal repertoire (Michetti, 2012), are detected in several genetic mouse models of NDDs (Bozdagi et al., 2010; Romano et al., 2013; Scattoni et al., 2008; Schmeisser et al., 2012; Wohr et al., 2012; Won et al., 2012; Yang et al., 2012). When evaluating development of vocal response, it is crucial to consider potential confounders, as altered body temperature, weight and growth can affect both quantitative and qualitative UVSs (Bozdagi et al., 2010; Hamilton et al., 2011; Romano et al., 2013; Roy et al., 2012; Shair et al., 2003; Veenstra-VanderWeele et al., 2012; Yang et 
al., 2012). Overall, pup USV characterization permit identification of an ASD-like phenotype at an early stage of development, in situations when other social or behavioral phenotypes are difficult to obtain.

\subsection{Rodent models of repetitive behavior and motor stereotypies}

One of the symptoms of ASD and some other NDDs is restricted/repetitive patterns of behavior, interests or activities, manifested by stereotypic motor movements (i.e., repetitive sequences of motor behavior, topographically and morphologically invariant, often rhythmical), inflexible adherence to routines, ritualized patterns and circumscribed or perseverative interest (American Psychiatric et al., 2013). In general, repetitive behaviors can be divided in two classes, roughly indicating 'lower-order' (repetition of movements and stereotypies) and 'higher order' (insistence on sameness, lack of behavioral flexibility, with a distinct cognitive component) responses (Lewis et al., 2007). Although rodents exhibit several spontaneous motor stereotypies (e.g., excessive vertical jumping, back-flipping, circling, digging, chewing), excessive self-grooming behavior has been by far the most well-studied stereotypy in ASD mouse models (Fig. 2), likely because it is a common phenotype with a complex 'patterned' sequential nature, and is easy to measure in rodents (Crawley, 2007; Creese and Iversen, 1975; Kalueff et al., 2007a; Korff and Harvey, 2006; Lewis et al., 2007; McFarlane et al., 2008; Moy et al., 2008; Pogorelov et al., 2005; Turner et al., 2001), also see Table 2.

Recapitulating behavioral perseveration, pathological self-grooming in rodents can also be valuable for examining neural pathways of NDDs (Pearson et al., 2011; Reynolds et al., 2013; Silverman et al., 2010a). For example, ephrins A (ephrin-A ligands), ephrin A receptors (members of the receptor protein-tyrosine kinase superfamily) and their genes are strongly implicated in neural development (Wurzman et al., 2014). Serving as an important membrane-anchored cellular protein, ephrin A modulates neuronal differentiation and synaptic plasticity, and ephrin-A2/A3 receptor double knockout mice display repetitive self-grooming, motor retardation and social deficits, 
recapitulating some clinical symptoms of ASD (Wurzman et al., 2014). Similarly, exaggerated selfgrooming is seen in the inbred BTBR mice, displaying callossal agenesis, social deficits and behavioral inflexibility relevant to ASD (Amodeo et al., 2014; Brodkin et al., 2014). Interestingly, cholinergic agents which correct some clinical ASD symptoms (Van Schalkwyk et al., 2015) predictably reduce self-grooming (Amodeo et al., 2014) and other ASD-like behaviors (Karvat and Kimchi, 2014) in BTBR mice, whose self-grooming is also corrected by glutamatergic drugs (Silverman et al., 2012; Silverman et al., 2010a).

Several other candidate 'NDD' genes include the SHANK family - SHANK1, SHANK2 and SHANK3 (Guilmatre et al., 2014) modulating synaptic function in the brain. In addition to ASD-like social deficits and repetitive behaviors, Shank mutant mice display aberrant grooming (Schmeisser, 2015) including elevated repetitive self-grooming in Shankl+/- and -/- (Sungur et al., 2014), Shank2-/- (Schmeisser et al., 2012)'(Won et al., 2012) and Shank3-/- mice (Peca et al., 2011; Wang et al., 2011; Yang et al., 2012). Ablation of the GABA-synthesizing enzyme glutamic acid decarboxylase (Gad67) also results in mouse ASD-like behavior, including increased self-grooming and cognitive and social deficits (Zhang et al., 2014).

Related to grooming phenotypes, barbering (behavior-induced hair loss, Fig. 2), including both hetero- and self-barbering, can be used to assess repetitive behaviors (Kalueff et al., 2006). Note, however, that stressors and other laboratory environment factors (e.g., poor housing, nutrition/diet, lack of enrichment) may often trigger such behaviors in laboratory rodent colonies (Garner et al., 2011), (Dufour et al., 2010), (Garner et al., 2004), and therefore should be carefully monitored to avoid confusion with NDD-related behaviors. Another rodent paradigm widely used in the context of repetitive behavior is the marble burying test, which measures repetitive behavior related to digging, not correlated with anxiety traits and primarily stimulated by novelty (Thomas et al., 2009). Notably, motor repetitive behaviors, such as self-grooming and marble burying, are often more sensitive (than social responses) in testing different drugs in NDD mouse models (e.g., mGluR5 antagonists 
(Silverman et al., 2012; Silverman et al., 2010a) and acetylcholine esterase inhibitors (Amodeo et al., 2014) in BTBR mice), raising the questions of potential differential sensitivity of various NDD phenotypes to drugs.

\subsection{Rodent models of restricted interests and behavioral inflexibility}

Because ASD patients often follow fixed routines and resist changes (Chen et al., 2009; Frith et al., 1991; Goldman et al., 2009), such restricted interests and behavioral inflexibility can be modeled in rodents by assessing their motivation to explore novel objects and to nose-poke holes in the wall or floor (Elsabbagh et al., 2013). Perseverative exploration of only a limited set of (rather than all) available objects or holes may resemble restricted interests in ASD humans (Moy et al., 2008). Thus, it is possible to model this insistence on sameness in mice by assessing their flexibility to switch from an established habit to a new habit through reversal learning in the T-maze or Morris

water maze. Briefly, after establishment of a spatial habit (e.g., reinforcing entries into the left arm of a T-maze or locating the hidden escape platform in one quadrant of a Morris water maze), the experimental set is changed and the mouse is requested to abandon the previously acquired habit and shift to a new location. ASD mouse models displaying repetitive behaviors usually perform well during the acquisition phase, but are generally slower in the acquisition of the new information during the reversal phase (Bader et al., 2011; Gandal et al., 2012; Guariglia and Chadman, 2013; Karvat and Kimchi, 2012; Lee et al., 2013; Moy et al., 2007; Penagarikano et al., 2011; Sala et al., 2013; Sala et al., 2011; Wang et al., 2011; Zhao et al., 2010). Other, more complex and refined rodent attentional set shifting tasks continue to be developed in mice (Colacicco et al., 2002), (Garner et al., 2006) and rats (McAlonan and Brown, 2003) to target cognitive deficits associated ASD, ADHD and other NDDs (Tait et al., 2014), (Scheggia et al., 2014).

\subsection{Rodent behavioral tests targeting comorbid traits}

Together with core symptoms, NDD patients often present comorbid traits, including seizures, altered emotional and sensory processing, as well as sleep and gastrointestinal deficits (Fassio et al., 
2011; Gilby and O'Brien, 2013; van Steensel et al., 2011; Woolfenden et al., 2012). However, their underlying biological mechanisms remain poorly understood. For example, if comorbid traits are integral to the NDD (Argyropoulos et al., 2013), many of them must also be present in valid NDD mouse models, and assessed as associated symptoms (Crawley, 2007; Roullet and Crawley, 2011). The presence of comorbid phenotypes, such as seizures or altered anxiety levels, may also interfere with spontaneous behavioral responses, thus confounding the interpretations of results (Roullet and Crawley, 2011). Evaluation of comorbid traits (selected on the basis of the information already available on the phenotype or on the basis of the role played by the gene alteration on CNS function) is therefore critical for a fine-grain behavioral characterization of NDD mouse models.

For example, seizures are observed in 8-25\% of the ASD population (Hara, 2007; Jeste, 2011; Sansa et al., 2011), and are particularly common in ASD patients with ID (Woolfenden et al., 2012). The presence of seizures can be evaluated in mice using tonic-clonic rating scales or EEG recordings. Seizures can be spontaneous or drug-induced, and once started, interrupt normal activities such as walking, exploring, sniffing and grooming (Morrison et al., 1996). The brain activity recordings permit the evaluation of the neuronal activity and identify the seizures as a spike-wave pattern (Blundell et al., 2009; Chemelli et al., 1999; Zhou et al., 2009). Seizure susceptibility and high levels of seizures have been reported in several ASD mouse models, including Shank3B, CNTNAP2, Pten and Gabrb3 knockout mice (DeLorey et al., 1998; Peca J et al., 2011; Penagarikano et al., 2011; Zhou et al., 2009). In line with this, some epileptic strains, such as Synapsin I (Syn1) and Synapsin II (Syn2) knockout mice, show ASD-like traits (Greco et al., 2013), collectively emphasizing the overlap between this NDD and epileptic pathogenesis.

Anxiety is also common in NDD patients (Argyropoulos et al., 2013; Gillott et al., 2001; van Steensel et al., 2011), and standardized mouse assays to measure anxiety-like behaviors are primarily based on approach-avoidance conflicts since mice are nocturnal and avoid lit open novel environments. Currently, the most popular anxiety-related tests include the elevated plus-maze and 
light-dark tests, recently reviewed in (Cryan and Holmes, 2005; Griebel and Holmes, 2013). The elevated plus maze consists of two open and two enclosed arms, and the light-dark test represents a two-compartment apparatus with a dark enclosed and an open lit compartments. An unusually high preference for 'protected' closed arms and for 'safe' dark compartment is considered as an excessive anxiety-like trait. Interestingly, several ASD mouse models, such as the Nlgn2, 5HTT, FMRl, Avprlb, Shank2, Shank3 and other mice with mutations that may be relevant to autism, show increased anxiety profiles, in addition to at least one other core symptoms (Blundell et al., 2009; Holmes et al., 2003; Peca J et al., 2011; Schmeisser et al., 2012; Spencer et al., 2005; Wersinger et al., 2002; Won et al., 2012).

Finally, mounting evidence suggests early motor abnormalities in ASD neonates and children (Iverson and Braddock, 2013; LeBarton and Iverson, 2013; Phagava et al., 2008) and infants at increased risk for ASD (Leonard et al., 2013). Since motor dysfunction can affect other NDD symptoms, preclinical studies in mouse models have recently addressed this issue by fine-grain characterization of spontaneous motor behavior (De Filippis et al., 2010; Romano et al., 2013). This may be important as a behavioral biomarker of NDD at an early stage of development, when other behavioral phenotypes are difficult to record.

\subsection{Rodent models relevant to Tourette syndrome}

A common NDD, Tourette syndrome is a highly heritable, early-onset illness (American Psychiatric et al., 2013) characterized by motor and phonic tics - habitual sudden, rapid, recurrent and non-rhythmic movements or vocalizations (Yu et al., 2015). Often comorbid with other NDDs such as ADHD and ASD, clinical Tourette syndrome frequently overlaps with obsessive-compulsive disorder (OCD), anxiety and depression ((APA), 2013; Felling and Singer, 2011). Given excellent recent expert reviews of animal models of Tourette syndrome in this journal (Macri et al., 2013b),(Bronfeld et al., 2013), (Martino and Laviola, 2013), they will be only briefly mentioned here. Several mouse models have recently been proposed as relevant to Tourette syndrome, including DAT-/- mice with 
elevated dopaminergic tone, overall hyperactivity and stereotyped self-grooming patterns, which parallel inflexible behavioral actions in Tourette patients (Berridge et al., 2005; Denys et al., 2013). Mutant mice lacking $\mathrm{D}_{1 \mathrm{~A}}$ receptors display aberrant behavior including shorter (and more incomplete) grooming episodes with disrupted sequential patterns (Cromwell et al., 1998), potentially relevant to dopaminergic deficits in Tourette syndrome. Other brain neuromediators, including glutamate, serotonin, GABA, norepinephrine (NE) and histamine, play an important role in clinical Tourette's syndrome and its preclinical models (e.g., (Nordstrom et al., 2015), (Macri et al., 2013a), (Rapanelli and Pittenger, 2015)). For example, histidine carboxylase is an enzyme producing histamine from histidine. In line with clinical data implicating mutations in the human histidine decarboxylase (HDC) gene in Tourette syndrome (Castellan Baldan et al., 2014), the Hdc-/- mice recapitulate some aspects of this syndrome, including tic-like stereotypic grooming ( $\mathrm{Xu}$ et al., 2015b). Together with the growing number of animal models of Tourette syndrome and other tic disorders (Macri et al., 2013a),

(Godar et al., 2015), (Xu et al., 2015a), this suggests that future translational research will generate significant insights on these NDDs.

\subsection{Selected rodent models of attention deficit and hyperactivity}

Novel insights into the genetics and neurobiology of ADHD have already benefitted from animal models, and will be discussed here in the context of NDDs. Perhaps, the most robust and easiest ADHD symptom to measure in animal models is motor hyperactivity (hyperlocomotion). The control of hyperactivity is crucially linked to dopamine signalling, and both increased (Antrop et al., 2000; Corkum et al., 2001; Porrino et al., 1983) and decreased dopamine (Giros et al., 1996; Viggiano et al., 2002) can lead to hyperactivity in animal models. Other measurements of ADHD-like behavior, including inattention and increased impulsivity, are more difficult to model (see further), suggesting that most animal paradigms represent "ADHD-like" rather than complete "ADHD" models (Sontag et al., 2010). For example, the spontaneous hypertensive rat (SHR) created by selectively inbreeding rats of the Wistar-Kyoto (WKY) strain (Okamoto and Aoki, 1963) shows face 
validity for some aspects of $\mathrm{ADHD}$, including hyperactivity in a novel environment, excessive responses during a fixed interval/extinction schedule and difficulty in operant learning (Mook et al., 1993; Sagvolden, 2000; Wyss et al., 1992). Paralleling core symptoms of ADHD (hyperactivity, impulsivity and inattention), SHR are also less responsive to delayed reinforcement than WKY controls. Their behavioral alterations can be rescued by amphetamine (Myers et al., 1982; Sagvolden et al., 1992), methylphenidate (MPH) (van den Bergh et al., 2006) and the $\alpha 2$-agonist guanfacine (Sagvolden, 2006) providing further links to the human disorder. The SHR also demonstrate construct validity for ADHD, as their behavioral phenotypes are likely caused by altered dopamine signalling. SHR carry a 160-base pair insertion in intron 2 of the DAT gene Dat/Slc6a3, possibly affecting its expression in a manner similar to the VNTR seen in human ADHD patients (Vandenbergh et al., 1992). SHR have several abnormalities in cathecholaminergic function, including reduced release of dopamine in the prefrontal cortex, nucleus accumbens and striatum, decreased dopamine turnover in the substantia nigra, ventral tegmentum and frontal cortex (Russell, 2002) and elevated norepinephrine in several brain areas (De Villiers et al., 1995). Nevertheless, despite its excellent attributes, the SHR is not the best ADHD model. For example, the background WKY rat strain is less active (than other rats) and does not perform well on some tasks (van den Bergh et al., 2006) making the behavioral alterations in SHR seem more pronounced. The high blood pressure (hypertension) seen in SHR is not observed in ADHD and could explain some of the behavioral alterations, including changes to learning and memory (Davids et al., 2003). In order to address this issue, a nonhypertensive WKHA strain has been generated by back-crossing SHR rats to the WKY strain. However, while WKHA rats are hyperactive, they do not respond to MPH treatment, suggesting that they may not have predictive validity for ADHD (Hendley and Ohlsson, 1991). In general, despite its limitations, the SHR fulfils many of the criteria needed in an ADHD-like animal model, suggesting that further study may bring even more insights into the etiology of the disease. 
Polymorphisms in the DAT gene have been linked to susceptibility for ADHD in a number of clinical studies. The Dat knockout (Dat-/-) mice show a spectrum of ADHD-like phenotypes including hyperactivity in a novel environment, a reduction of startle response and an impairment of learning and memory (Giros et al., 1996; Sora et al., 1998; Zhuang et al., 2001) (also see details of heterozygous Dat+/- mouse phenotypes in (Kalueff et al., 2007c)). The behavioral symptoms of Dat/- mice can be rescued by both amphetamine and MPH (Gainetdinov et al., 1998). Nevertheless, although DAT is linked to ADHD clinically, Dat knockout mice may not represent a good ADHDlike model due to an extreme phenotype, such as a 5-fold increase in dopamine levels in the striatum of these mice coupled to compensatory changes in other dopaminergic signalling pathways. There is also increased activity of tyrosine hydroxylase (Jaber et al., 1999) and down-regulated expression of postsynaptic dopamine D1 and D2 receptors (Gainetdinov et al., 1998). This phenotype is at odds with the presumed pathology of clinical ADHD (which suggests reduced dopamine in the prefrontal cortex) and the postulated therapeutic action of many anti-ADHD drugs (including MPH and amphetamine) via DAT. Although the behavioral phenotype of Dat knockout mice can also be rescued by SSRIs, non-selective serotonin agonists and 5-HT2A antagonists (Barr et al., 2004), SSRIs are not particularly effective in controlling major disordered symptoms of ADHD clinically. Finally, due to their highly hyperactive phenotype, memory and learning testing is almost impossible to perform in Dat-/- mice, which also show unwanted growth retardation and an increased likelihood of premature death (Gainetdinov et al., 1998; Giros et al., 1996). Notably, Dat knock-down mice, which only have $10 \%$ of normal Dat function, also show hyperactivity, anti-hyperkinetic responses to amphetamine, excessive grooming and tendency to persevere in walking in straight lines (Berridge et al., 2005).

The coloboma mouse has a radiation-induced mutation in the SNAP25 gene resulting in a 50\% reduction of SNAP25-mediated synaptic transmission. Heterozygous coloboma mutant mice $(\mathrm{Cm}+/-)$ show spontaneous hyperactivity reduced by amphetamine but not MPH (Hess et al., 1996). Coloboma 
mutants also display impulsivity and impaired inhibition in a delayed reinforcement task, being unable to wait as long as controls for a larger reward (Bruno et al., 2007). Mutation of SNAP25 reduces dopamine in the dorsal striatum, increases cortical dopamine and striatal and accumbal norepinephrine (Jones et al., 2001; Raber et al., 1997). Thus, an interaction between these two monoamines' signalling mechanisms seems to be important in coloboma mutants. These mice also seem to have predictive validity for ADHD, since identification of their SNAP25 mutation led to candidate gene studies that eventually revealed an association between the gene and human ADHD (Brophy et al., 2002). As a caveat, however, $\mathrm{Cm}+/$ - also have visual problems, while homozygous animals die early in pregnancy, these phenotypes are not associated with ADHD.

Finally, as an example of a developmental toxin that can lead to the symptoms of ADHD, rats lesioned with 6-hydroxydopamine (6-OHDA) on postnatal day 1 show hyperactivity and reduced learning at certain developmental period. 6-OHDA is a neurotoxin that is uptaken by the DAT and NE transporter, and selectively kills both types of neurons. Motor and learning defects of 6-OHDA rats can be rescued by applying amphetamine or MPH. The hyperactivity of 6-OHDA-lesioned animals is accompanied by reduced dopamine in the striatum, prefrontal cortex, midbrain and amygdala, and increased striatal serotonin (Luthman et al., 1989). However, the noradrenergic system does not appear to be altered in these animals. Notably, the behavioral phenotype of 6-OHDA rats normalizes by adulthood, demonstrating the ability of the dopaminergic system to recover from some lesions during early development (Davids et al., 2003).

\subsection{Developing translational models of NDDs using non-rodent species}

While rodents are an indispensable tool for NDD research (Homberg et al., 2015), other model organisms are gaining popularity in this field. For example, invertebrate models, such as fruit flies (Drosophila melanogaster), have traditionally been used in developmental and behavioral genetics, and while out of scope here, are be mentioned for their emerging potential in modeling 
NDDs, including ASD and ADHD (see (Kaur et al., 2015; van der Voet et al., 2015; Wise et al., 2015) for details).

Mounting evidence suggests zebrafish (Danio rerio) as a valuable translational model (Kalueff et al., 2014a; Stewart et al., 2014a) for behavioral analysis in both larval and adult fish and in-depth characterization of their rich behavioural repertoire (Kalueff et al., 2013; Kalueff et al., 2014b; Stewart et al., 2015a; Stewart et al., 2015d). The large number of mutant strains, as well as the availability of modern genetic, optogenetic and neuroimaging tools (Kalueff et al., 2014a; Kalueff et al., 2014b; Stewart et al., 2015d; Ullmann et al., 2015; Ullmann et al., 2010), make zebrafish an excellent model for studying NDDs. For instance, zebrafish have recently been suggested as a promising model of ASD (Stewart et al., 2014b), especially as fish spent $>80 \%$ of their time swimming together in shoals (Fig. 2D) and display robust kin recognition and social preference phenotypes (Kalueff et al., 2013). Similar to rodent models, zebrafish also display robust social preference, which can be easily tested in aquatic versions of social interaction and social preference paradigms discussed above for rodents (Fig. 2). Additionally, multiple pharmacological, genetic and environmental manipulations can disrupt zebrafish shoaling behavior (Stewart et al., 2014b). The ability to swim in a stereotypic manner (e.g., corner-to-corner, as after treatment with nicotine, or in tight circles, as after treatment with glutamatergic antagonists ketamine, MK-801 or phencyclidine (Stewart et al., 2015b)), raises the possibility of using zebrafish as models of repetitive behaviors, relevant to motor symptoms of ASD and other NDDs.

Despite the numerous advantages of zebrafish for developmental neuroscience, there are currently very few ADHD-related models in zebrafish. Hyperactivity is arguably the easiest ADHDrelated phenotype to assess in zebrafish, presenting as increased distance travelled, velocity and movement frequency/duration in both adult (Blaser et al., 2009; Lopez-Patino et al., 2008) and larval fish (Chen et al., 2011; Norton, 2011; Saili et al., 2012; Seibt et al., 2010). Even fewer studies targeted impulsivity and inattention in zebrafish, most likely reflecting challenges of designing 
specific tests (Parker et al., 2012) and the general under-appreciation of zebrafish as a behavioral model of NDDs. Several successes, however, indicate the growing potential of zebrafish models of ADHD. For example, morpholino-mediated inhibition of $n r 4 a 2$, an ADHD-linked dopaminergic orphan nuclear receptor (Saili et al., 2012), during development leads to permanent hyperactivity (Blin et al., 2008). A recently developed 5-choice serial reaction time task (5CSRTT) can measure impulsivity in zebrafish similar to rodents (Parker et al., 2014b; Parker et al., 2014c; Parker et al., 2012). To analyze the role of ADHD-linked genes in zebrafish phenotypes, the latrophilin 3.1 (lphn3.1) gene has been comprehensively evaluated during zebrafish development (Lange et al., 2012b). LPHN3 is an orphan adhesion-G protein-coupled receptor whose gene contains a variation that conveys a risk haplotype for ADHD (Arcos-Burgos et al., 2010). latrophilin3.1 represents a zebrafish homolog of human $L P H N 3$, expressed in the brain up to $6 \mathrm{dpf}$. The reduction of its function during zebrafish development by injecting morpholinos results in hyperactive phenotype of the morphants, also displaying more bursts of acceleration (increased motor impulsivity) - the two ADHD-like phenotypes rescued by anti-ADHD drugs MPH and atomoxetine (Lange et al., 2012b) (Fig. 2). Together with some other recent interesting genetic models (e.g., (Huang et al., 2015)), this illustrates the growing utility of zebrafish in modelling ADHD and other NDDs.

Chick models are also gaining popularity in neurodevelopmental research, especially since they display robust social, motor and cognitive phenotypes relevant to clinical NNDs (Fig. 2E) and demonstrate critical disease 'susceptibility' windows during the neural development (Koshiba et al., 2013a; Mimura et al., 2013; Mimura, 2013). For example, chicks display high preference for social groups (like rodents), and emit social vocalizations (e.g., 'alarm' and 'joy' calls when isolated or meeting peers, respectively (Koshiba et al., 2013c)). Social environment is particularly important for chicken normal behaviors and their overall sensitivity to environmental stressors (Koshiba et al., 2013a; Mimura et al., 2013; Mimura, 2013). For example, deficit of peer rearing affects monoaminergic systems in young chicks, evoking depressive-like behaviors (Koshiba, 2013; 
Shirakawa, 2013b) and suppressing forebrain growth around critical susceptible age (Koshiba et al., 2013a).

Non-human primate models, such as those based on common marmoset (Callithrix jacchus), represent another promising area of NDD research (Fig. 2E). Marmosets display rich vocal communication with approximately 10 types of 'calls', likely representing (based on contexts) positive or negative emotional states (Koshiba et al., 2011; Koshiba et al., 2013b). Together with parallel assessment of vocalizations and behaviors, the socio-behavioral trajectories in marmosets have recently been studied using multivariate repression. For example, such analyses revealed important time windows around weaning, critical for establishing normal social and motor behaviors, also showing pathological hyperactivity in marmosets if reared without adequate social environment (Koshiba et al., 2013b). Light-induced disruption of the young marmoset circadian rhythm affects their adult behaviors, leading to more 'hyperactive' patterns of social and motor activity (Koshiba et al., 2015b; Senoo et al., 2011) (also see the link between marmoset emotional responses, body temperature (Karino, 2015; Koshiba, 2013; Shirakawa, 2013a) and hormones (Koshiba et al., 2011), Fig. 2E).

\section{Selected emerging translational questions}

A complex, systems biology-based approach that parallels clinical studies, preclinical animal models, biomarker discovery and mechanistically-driven in-vitro research is becoming increasingly critical for improving our understanding of brain disorders and their therapies (Cryan and Slattery, 2007; Kalueff and Stewart, 2015; Kalueff et al., 2015; Kalueff et al., 2007d; Redei et al., 2001; Stewart and Kalueff, 2015). As outlined here, marked progress in studying NDDs has been achieved through translational analyses using preclinical (animal) models and tests (Table 1) (Homberg et al., 2015). However, more work is needed in order to fully understand the pathobiology of NDDs. For example, while the opportunity of targeted genetic manipulations in mice resulted in significant advances in our understanding of genetics and biology of NDDs, the availability of genetically altered 
rat models (especially due to the development of modern gene-editing approaches, such CRISPRCas9 or Zinc-Finger Nuclease (ZFN) technologies) may significantly further the progress in the field (Kaneko and Mashimo, 2015), (Parker et al., 2014a). Beyond their obvious advantage of larger size, rats have a wider range of well established complex behavioral paradigms (compared to mice), particularly critical to evaluate fine behaviors, cognitive function and emotionality, critical for NDD research (Parker et al., 2014a). The Panel recognizes the importance of genetically modified rats in studying a wide spectrum of NDDs and other brain disorders (Kalueff et al., 2010). Several additional, emerging challenges can be relevant to building translational bridges in this field. Thus, while we may not be able to provide definite answers to these questions at present, their discussion can benefit future studies of NDDs.

\subsection{Making research more translational: from lab to bedside}

Discussion of translational NDD models would be incomplete without mentioning clinical studies utilizing behavioral approaches and biomarkers similar to those developed for rodents, zebrafish, chicks and non-human primates (see above). One interesting example of such translational bridge is "reverse translation", or "bedside to bench", experiment performed in patients with psychiatric disorders (schizophrenia and bipolar disorder) by analysing their behavioural pattern of activity and directly comparing them with the behavioral pattern of mutant mice (e.g., hyperactive DAT knockouts) recorded in similar conditions (Perry et al., 2009), (Perry et al., 2010). Such translational angle is also important given the need to develop 'early' and 'very early' behavioral and physiological biomarkers of clinical NDDs. For instance, multivariate analyses of neurological development across age in normal infants vs. infants with aberrant neural development shows correlation of physiological biomarkers (blood and brain imaging data) with specific behavioral phenotypes, such as head control and rolling behavior (Fig. 2F) (Koshiba et al., 2015a). This raises the possibility of using such phenotypes as potential 'early' behavioral biomarkers of NDDs (Koshiba et al., 2015a), crucial in the absence of other, more complex behaviors to aid diagnostics. This is 
particularly important because early neural development represents a critical window for maximizing the success of therapeutic intervention. Finally, the development of video-tracking and other behavior-recording methods (e.g., those utilizing smart phones (Mimura et al., 2015)) to study older children and adults further fosters NDD research and extraction of novel behavioural biomarkers (Fig. 2F).

\subsection{Moving from single- to poly-phenotype models}

As already mentioned, the majority of NDDs are multi-factorial brain illnesses with many genetic and environmental determinants. Therefore, a conceptual approach deconstructing these disorders into simpler and easily quantifiable phenotypic units ('endophenotypes') is a reasonable strategy (Gottesman and Gould, 2003; Gould and Gottesman, 2006; Lenzenweger, 2013). The endophenotype concept has been successful in dissecting various brain disorders, their overlapping and unique symptoms, as well as candidate biomarkers and genes across the disorder spectrum (Courtet et al., 2011; Crossley et al., 2014; Ikeda et al., 2013; Ivleva et al., 2010); also see (Kalueff et al., 2008b; Kalueff and Stewart, 2015; Kalueff et al., 2015; LaPorte et al., 2010; Stewart and Kalueff, 2015) for detailed discussion. Recognizing that multiple phenotypes can be shared by several distinct disorders, such strategy is in line with the recently suggested research domain criteria, RDOCs (Casey et al., 2013; Cuthbert and Insel, 2010; Insel et al., 2010; Insel, 2014) that target phenotypic dimensions, rather than categories, of psychiatric diagnoses (Gottesman and McGue, in press; Kalueff et al., 2015). However, in parsing individual endophenotypes across and within the disorders in both clinical and preclinical models, the predominant focus of biological psychiatry continues to be narrow and phenotype-centered (Ditzen et al., 2012; Filiou et al., 2011; Gormanns et al., 2011; Kalueff et al., 2008b; Maccarrone et al., 2013). From a conceptual standpoint, if a CNS disorder consists of several distinct endophenotypes $\mathrm{A}, \mathrm{B}$ and $\mathrm{C}$, then focusing on clinical and preclinical models or tests that target more than one endophenotype (e.g., A and B or A, B and C) is better than using experimental models or clinical studies that assess only one. Using ASD as an example, an animal model is likely 
more valid if it assesses both social deficits and behavior perseverations, as compared to a model with only one aberrant phenotype. A growing number of studies are already embracing this approach, monitoring several distinct endophenotypes of a disorder and discovering their biomarkers and potential treatments (Amodeo et al., 2014; Burket et al., 2013; Kalueff et al., 2015; Pearson et al., 2011; Reynolds et al., 2013; Silverman et al., 2010a) (Fig. 4). The main challenge, however, is that it may be insufficient to dissect 'unique' molecular mechanisms of endophenotypes $\mathrm{A}, \mathrm{B}$ and $\mathrm{C}$ from their 'shared' pathways (e.g., A+B or B+C) because, as suggested recently (Kalueff et al., 2014c; Kalueff et al., 2015), principally novel genetic and molecular 'cross-talk' pathways may underlie the pathogenetic coupling of such endophenotypes (e.g., 'A<->B' or 'B<->C') without affecting each endophenotype per se (Fig. 4). Remaining to yet be established, the putative mechanisms by which such novel classes of genes act, may include synchronizing or synergizing several distinct disordered processes (Stewart et al., 2015c). Applying this concept to NDDs, it is possible that in clinical or experimental ASD, social deficits can be pathogenetically linked to repetitive behaviors via cross-talk molecular mechanisms. Likewise, in addition to its hallmark symptoms - hyperactivity and attention deficit - ADHD may rely on additional molecular networks integrating the two endophenotypes together, thus making it the single well-defined clinical disorder. Complementing current theories of NDDs, the pathological linkage between several distinct disordered endophenotypes, in addition to focusing on them separately or in combination, merit further scrutiny (Fig. 4). For example, this can be achieved by applying a network-based 'cloud' approach to modeling NDDs, where individual endophenotypes (as well as biomarkers and disorders) are not only assessed in clinical and preclinical studies individually or in combinations, but are assessed by novel linkages between them (Fig. 4). Based on this rationale, clinical cases with two synchronized phenotypes (e.g., repetitive behaviors and social deficits in ASD) may demonstrate a stronger (and, therefore, more debilitating or treatment-resistant) NDD, compared to cases when core endophenotypes are expressed in less organized manner (Fig 4, therefore, implying their weaker pathogenetic integration and less 
pronounced overall pathogenesis). Clearly, this necessitates further integrative clinical studies and respective innovative preclinical models of NDD pathogenesis.

\subsection{Monoamines as neurotrophic factors: lessons from serotonin}

While brain neurotransmitters play a key role in NDDs, it is often overlooked that in early development they also act as neurotrophic factors (Homberg et al., 2010). As one illustrative example, consider the serotonergic system - a target of many pharmaceutical agents (e.g., antidepressants and antipsychotics) used to treat NDDs, with multiple genetic polymorphisms conferring the risks for NDDs (Lesch and Waider, 2012). Although the precise role of serotonin in NDDs is not fully understood, it mediates aversive processing (Deakin and Graeff, 1991), behavioral inhibition (Cools et al., 2008) and social behavior (Kiser et al., 2012), which are often affected in NDDs. The common underlying function of serotonin may be the modulation of sensitivity to environmental stimuli (Homberg, 2012), a role mostly ascribed to serotonin acting as a neurotransmitter. However, serotonin also acts as an important neurotrophic factor during early development (Gaspar et al., 2003), and may shape brain circuits involved in these processes. The latter function is likely to be critical for NDDs.

Serotonin is first generated in the developing brain at mid-gestation, by serotonergic neurons in the raphe nuclei of the brainstem, mediated by the neuronal isoform tryptophan hydroxylase 2 (TPH2) (Gaspar et al., 2003). Serotonin is synthesized from the essential amino acid tryptophan and packed into vesicles by vesicular monoamine transporter (VMAT), whereas SERT is responsible for the reuptake of serotonin into the presynaptic nerve terminal, and thereby determines synaptic serotonin levels (Kriegebaum et al., 2010). During development, circulating serotonin of gastrointestinal, placental and maternal origins produced by peripheral isoform $\mathrm{TpH} 1$ penetrate into the developing brain (Bonnin and Levitt, 2011). There it influences developmental processes, including cell division, differentiation and migration (Gaspar et al., 2003). These developmental processes may also involve non-serotonergic neurons, since SERT is transiently expressed in non- 
serotonergic cells in the brain during development (Homberg et al., 2010). Indeed, SERT is expressed in specific sets of glutamatergic neurons in the thalamus and in thalamocortical projection neurons, as well as in prefrontal cortex and hippocampus, and takes up extrasynaptic serotonin during perinatal CNS development, until approximately P14 (corresponding to the third trimester of human pregnancy) (Gaspar et al., 2003). This serotonin is expected to be derived from serotonin-producing raphe neurons traveling a long distance in the developing brain (Kullyev et al., 2010). The role of SERT in glutamatergic thalamocortical neurons is particularly well established, as SERT regulates sensory map architecture (Chen et al., 2015). For example, knockout of SERT in these neurons causes lasting alterations in thalamocortical axon patterning, spatial organizations of cortical neurons and dendritic arborization in sensory cortex (Gaspar et al., 2003). These developmental effects of serotonin are specific for non-serotonergic neurons, since SERT knockdown in serotonin-producing neurons does not impair barrel maps (Chen et al., 2015). Likewise, excessive serotonin levels in SERT knockout rats is associated with disrupted topographic patterning of both the barrel and visual cortex (Cases et al., 1996; Miceli et al., 2013; Murphy and Lesch, 2008; Persico et al., 2001). In addition, the outgrowth of raphe neurons to the prefrontal cortex and cortical layering are altered in SERT knockout rodents (Altamura et al., 2007; Witteveen et al., 2013). Behaviorally, SERT knockout is consistently associated with anxiety-like behavior (Kalueff et al., 2010) and impaired social interactions (Kiser et al., 2012), symptoms that are key to NDDs. In contrast, behavioral inhibition is reduced in rodents lacking SERT (Holmes et al., 2002; Homberg et al., 2007a). Thus, there is strong but indirect evidence that serotonergic genetic variance modulates neurodevelopmental processes involved in the pathogenesis of NDDs. In rodents, administration of SSRIs during pregnancy and during the first 2 postnatal weeks reduces social play in rats and alters sensory processing, cortical wiring and myelin sheet formation (Simpson et al., 2011; Xu et al., 2004). These findings resemble those associated with ASD (Deoni et al., 2015; Zikopoulos and Barbas, 2010) and SERT in rodents (Homberg et al., 2007b). SSRI exposure decreases cortical dendritic arbor 
complexity prenatally (Chameau et al., 2009; Smit-Rigter et al., 2012) while during P2-P11 it decreases dendritic complexity in the prefrontal cortex and evokes anxiety-like behavior (Rebello et al., 2014) (similar to SERT knockout rodents (Kalueff et al., 2010)). Thus, further research is needed to examine both the neurotransmitter and neurotrophic roles of serotonin and other brain neuromediators in NDD pathogenesis.

\subsection{Understanding gene-environment correlations and environmental enrichment}

Another problem to address in future translational studies is the potentially self-perpetuating nature of NDDs (Fig. 2B). For example, since aberrant neural development often results in debilitating NDD behavioral symptoms (e.g., social, cognitive or motor deficits) from early childhood, this disrupts normal social and affective interactions of an affected individual with their social environment (Fig. 2C). Accordingly, this can increase risks of the environment becoming more adverse for affected individuals. Because healthy social/environmental stimulation is important for shaping neural plasticity in maturing brain and for developing efficient behavioral adaptations from early age, the evoked social/environmental adversity may further impair neural development, worsening the existing NDD by creating a pathogenetic 'vicious circle' (Fig. 2). The recognition that the individual's exposure to the environment can be a function of their genotype, called GeneEnvironment correlations (Jaffee and Price, 2007), is relatively recent in biological psychiatry. Conceptually, it complements the widely accepted notion of Gene x Environment interactions (GxE), which reflect how genotypes modify the sensitivity to environmental factors (Duncan et al., 2014; Kalueff et al., 2007d; Le Strat et al., 2009). Highly relevant to NDD pathogenesis, the GeneEnvironment correlations (Fig. 2C) may have multiple clinical implications. For example, correcting behavioral strategies (e.g., pharmacologically or behaviorally) in ASD or ID children can improve their interaction with social environment at a 'critical' early age. Moreover, educating parents and peers on how to best deal with special needs patients can improve their integration into the society, therefore reducing 'early' environmental adversity. Collectively, this may not only improve clinical 
symptoms of the existing NDD, but, in parallel, prevent the risks of additional (e.g., stress/adversitytriggered) neurodevelopmental deficits (Fig. 2C). From a practical standpoint, a potential strategy to target Gene-Environment correlations in experimental models of NDDs can involve correlational analyses of social components displayed by multiple individuals in social interactions. Improvement of software tools to analyze social interactions of multiple animals in detail (e.g., assessing social components sequentially with a high time- and space- resolution) may significantly empower the assessment of Gene-Environment correlations in biological experiments. As the concept of GeneEnvironment correlations is gaining more recognition in neuropsychiatry (Jaffee and Price, 2007), the development of their experimental preclinical models may represent an important and novel strategic direction of NDD research (Homberg et al., 2015).

Paralleling clinical data on positive effects of cognitive and behavioral therapy in various NDDs (e.g., (Morand-Beaulieu et al., 2015), (Boyer et al., 2015)), the ability of early environmental interventions to reverse or rescue aberrant phenotypes in animal models of NDDs is particularly interesting (Nithianantharajah and Hannan, 2006). For example, Fmrl-knockout mice, a model of FXS, display hyperactivity and a lack of habituation that is rescued in animals raised in an enriched environment (Restivo et al., 2005). In mice deficient for Mecp2, a genetic model of Rett syndrome, early environmental enrichment rescued memory deficits, motor coordination and anxiety-like behaviors in a sex-specific manner (Lonetti et al., 2010), whereas environmental enrichment reversed the increase in repetitive self-grooming behavior in BTBR mice (Reynolds et al., 2013). Taken together, these preclinical studies further support the need to investigate a possible role for environmental treatments in alleviating the symptoms of NDDs.

\section{Conclusion}

In summary, while NDDs are triggered by aberrant neural development, their pathogenesis involves a complex interplay between developmental, genetic, endocrine, immune and neural abnormalities. The extensive research covered here illustrates the existing challenges in identifying 
the neurobiological basis as well as clarifying susceptibility, resilience and strategies for novel effective treatments of NDDs.

As already emphasized, both traditional 'rodent' mouse and rat models (extensively used in NDD research) are also increasingly complemented by the growing spectrum of alternative model organisms, including zebrafish, chicks and non-human primates. Overall, experimental animal models are critical to increase our understanding of NDDs, including studying behavior, neuronal morphology and gene expression patterns across developmental stages before and during the manifestation of disorders-related symptoms (Homberg et al., 2015). In addition, preclinical models permit the functional assessment of the impact of genes and gene networks at the level of genetic, synaptic and neuronal networks of cognition, behavior and neural systems. Paralleling clinical findings, such models begin to play a more critical role in gaining translational and mechanistic insights into NDD pathogenesis.

Acknowledgement: This study was coordinated by the International Stress and Behavior Society (ISBS) Task Force on Neurodevelopmental Disorders. The authors have no conflict of interest. We thank Matthew Singer (University of Idaho, USA) and Noldus IT (Wageningen, Netherlands) for providing the mirror test, shoaling and human behavior tracking illustration for this manuscript. SN, MK and HY are supported by Grants-in-Aid for Scientific Research (KAKENHI) of the Japan Society for the Promotion of Science (JSPS grants 25282221, 21200017, 25119509, 15K15404). This research is also supported by Guangdong Ocean University (AVK, CS), ZENEREI Research Center, St. Petersburg State University (internal grant 1.38.201.2014, AVK, RRG), Ural Federal University (Government of Russian Federation Act 211, contract 02-A03.21.0006; AVK), the Russian Science Foundation grant N14-15-00131 (RRG) and the Institute of Experimental Medicine RAS (VMK). 
Figure 1. The spectrum nature of neurodevelopmental disorders (NDDs). Panel A presents the spectrum of neurodevelopmental and other associated disorders. Panel B shows phenotypic domain structure and heritability of common NDDs (red - reduced, green - increased; also see Table 1). ASD - autism spectrum disorder, ID - intellectual disabilities, ADHD - attention deficit hyperactivity disorder, OCD - obsessive compulsive disorder, PTSD - post-traumatic stress disorder. Panel C summarizes the temporal dynamics of key neuronal processes related to neural development. Panel D illustrates typical onset of selected common neurodevelopmental disorders.

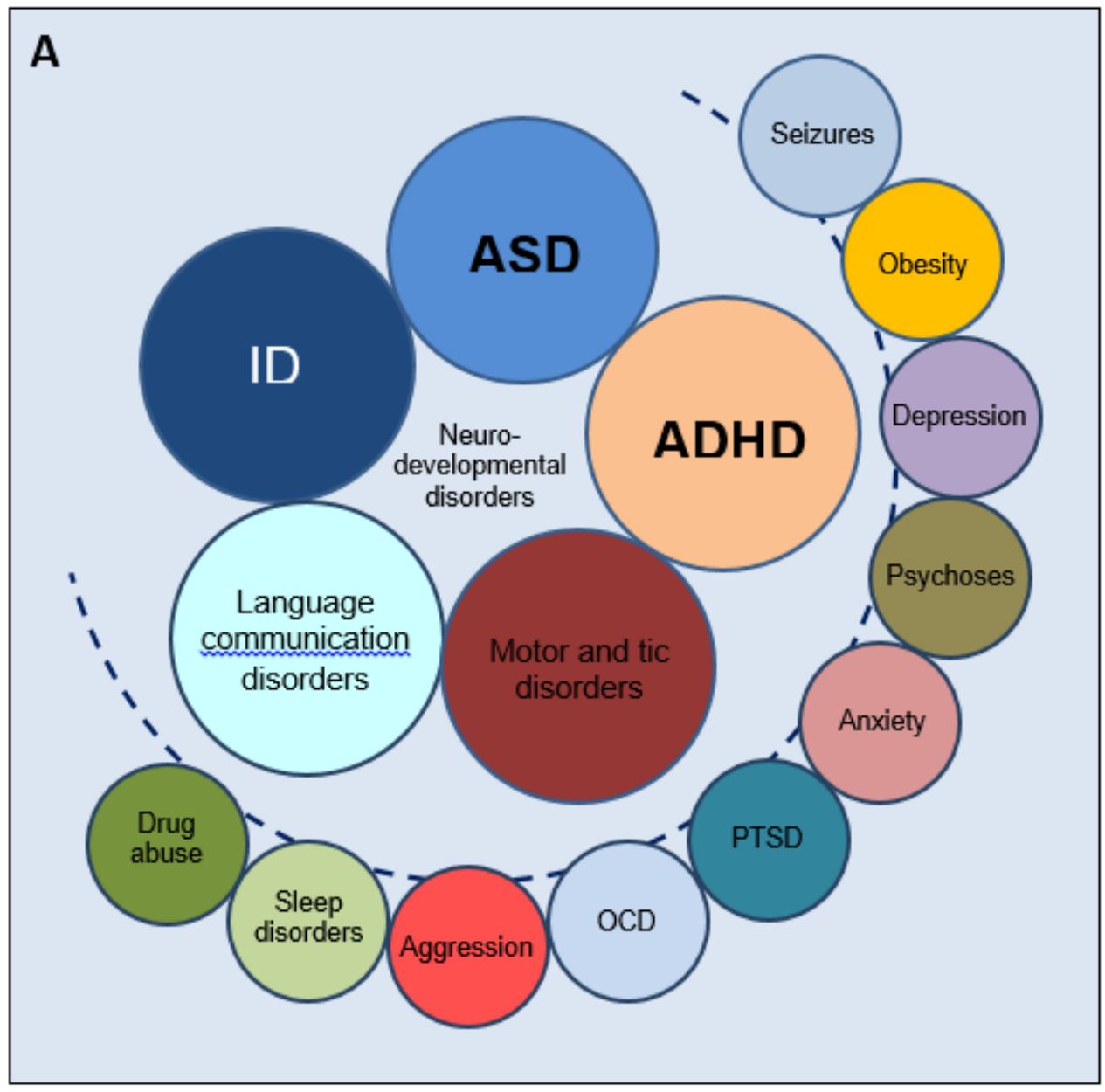


B

Disorders

Major affected behavioral domains

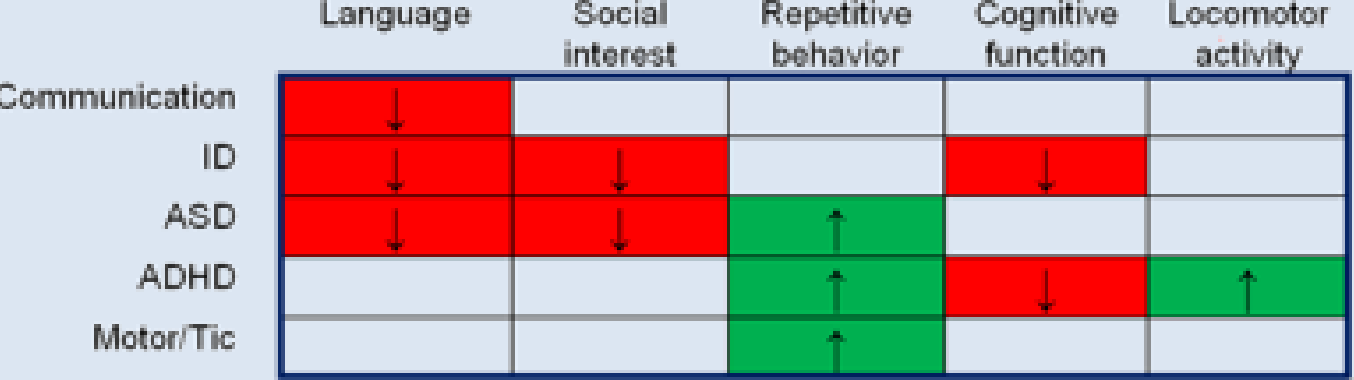

$\uparrow$ Heritability estimates

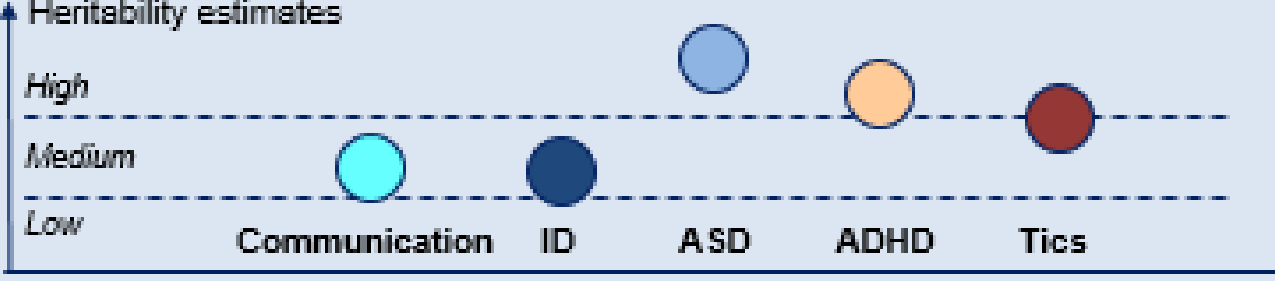

C

Neurodevelopmental events

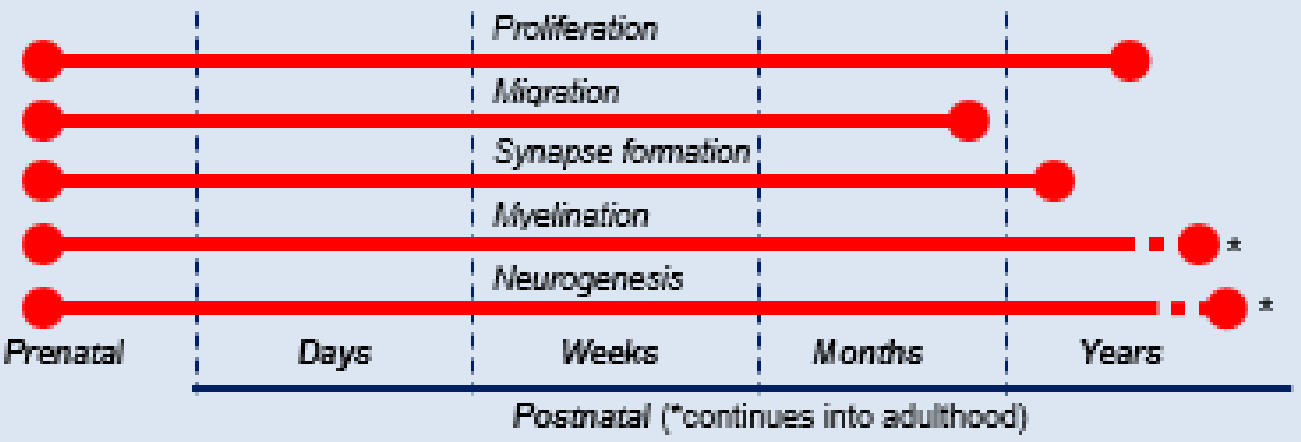

D ASD, Tic disorders, ID, Communication disorders

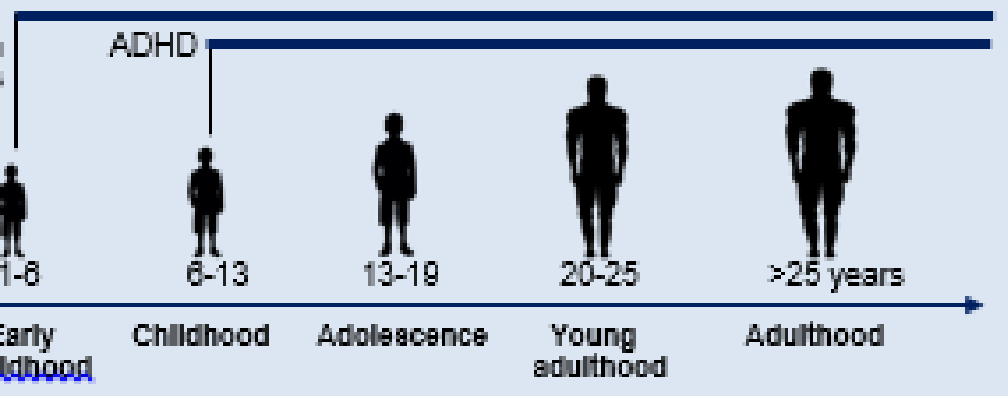


Figure 2. The growing clinical and preclinical importance of neurodevelopmental disorders

(NDDs). Panel A demonstrates global prevalence of NDDs and their costs (USA, \$B per year; Center for Disease Control/CDC, 2014). Panel B shows rapid growths in occurrence of NDDs, such as ASD and ADHD, in the last decade (ASD data represent prevalence in 8 year olds (2015) and ADHD data represent prevalence in children 3-17 years old (Bloom et al., 2013)). Panel C shows the relative 'health burden' of NDDs and other common human disorders, calculated as year-patients since the disorders' onset and based on average life expectancy of 80 years (AD - Alzheimer's disease, PD Parkinson's disease). Note that NDDs are among the most impactful disorders. Inset: the rapidly expanding biomedical research on NDDs in the last 20 years, based on Pubmed article search for 'neurodevelopmental' (December 2015). Panel D shows popular model organisms used in translational research on NDDs, and relevance of rodent and zebrafish behaviors to various phenotypic domains of these disorders. Rodent models of NDDs have been extensively discussed in the text. Note overt social, locomotor and repetitive (e.g., grooming, hetero- and self-barbering (Kalueff et al., 2007a; Kalueff et al., 2006)) behaviors in rodents. Illustrating the value of zebrafish models for NDDs, the bottom left section shows normal and aberrant ASD-like zebrafish shoaling behaviors (Stewart et al., 2014b). Botom right section illustrates an ADHD-related zebrafish model based on morphants with rediced fucntion of lphn3.1 gene encoding latrophilin 3 (note overall baseline hyperactivity associated with impulsive-like acceleation bursts, accompanied by reduced and mislaced dopaminergic neurons in the ventral diencephalon) (Lange et al., 2012a, c). Panel E illustrates social and cognitive behavioral tests used in preclinical NDD models based on domestic chicks (Koshiba et al., 2013a; Koshiba et al., 2013c; Koshiba, 2013; Mimura et al., 2013; Mimura, 2013; Shirakawa, 2013b) and common marmosets (Karino, 2015; Koshiba et al., 2011; Koshiba et al., 2015b; Koshiba et al., 2013b; Senoo et al., 2011; Shirakawa, 2013a). Paralleling human clinical studies in preterm infants and juveniles (Koshiba et al., 2015a; Koshiba et al., 2013b; Koshiba, 2013) , such models can also enhance biomarker discovery. For example, the posterior-lateral forebrain 
serotonin metabolite, 5-hydroxyindolacetic acid (5HIAA), correlates with chick freezing behavior (Koshiba, 2013; Shirakawa, 2013a), whereas emotional phenotypes in common marmosets correlate with venous blood progesterone in female adult common marmosets (Koshiba et al., 2011). Panel F illustrates several examples of clinical models of NDDs based on behavioral analyses (similar to those developed for non-human model organisms), including studying head control and body rolling in normal and neurologically affected infants or using computer games in older children (top row) (Koshiba et al., 2013b) and behavioral video-tracking of social and locomotor activity in normal vs. autistic 2-year old children (bottom row), image courtesy of Noldus IT (Netherlands).

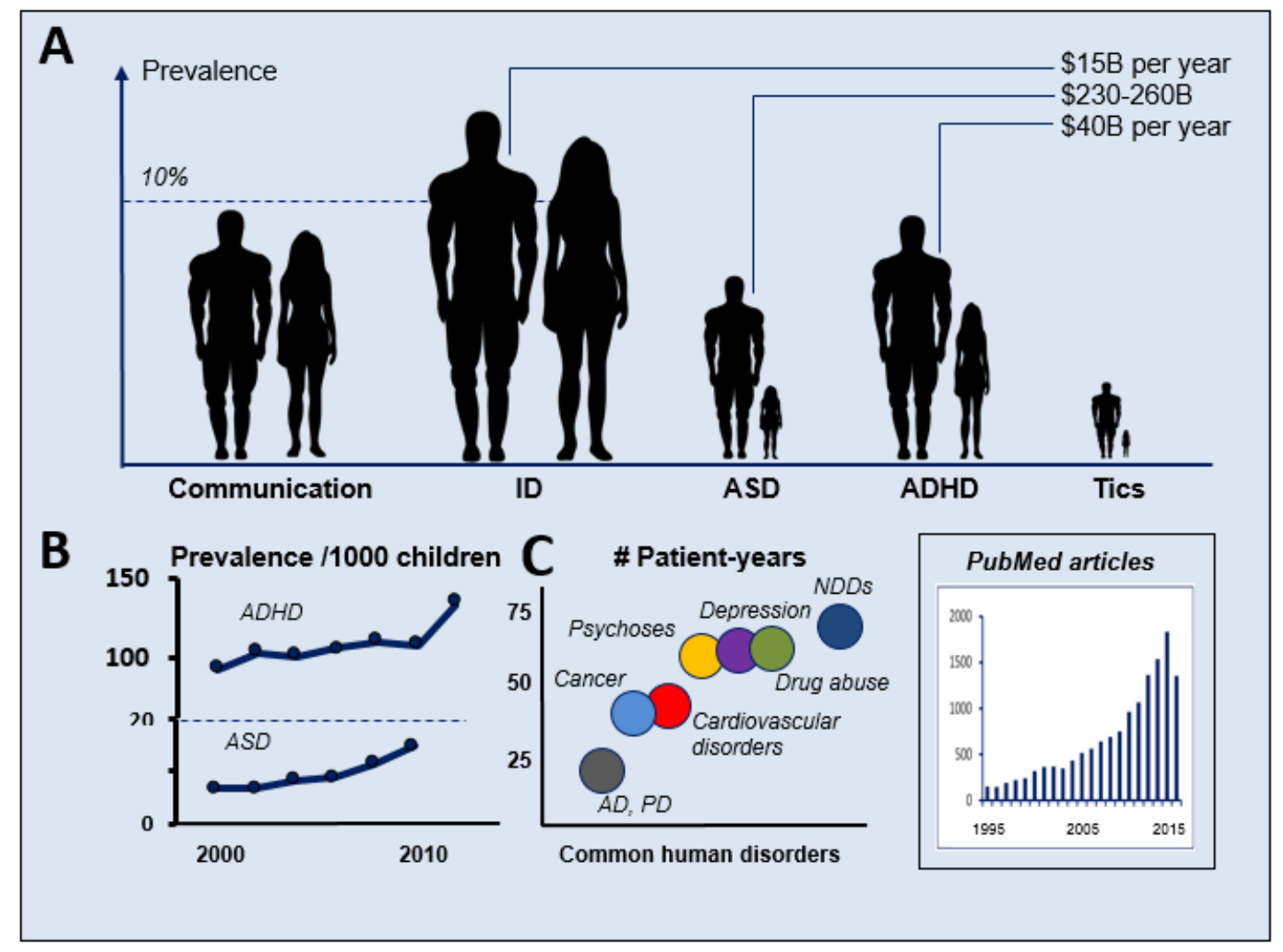




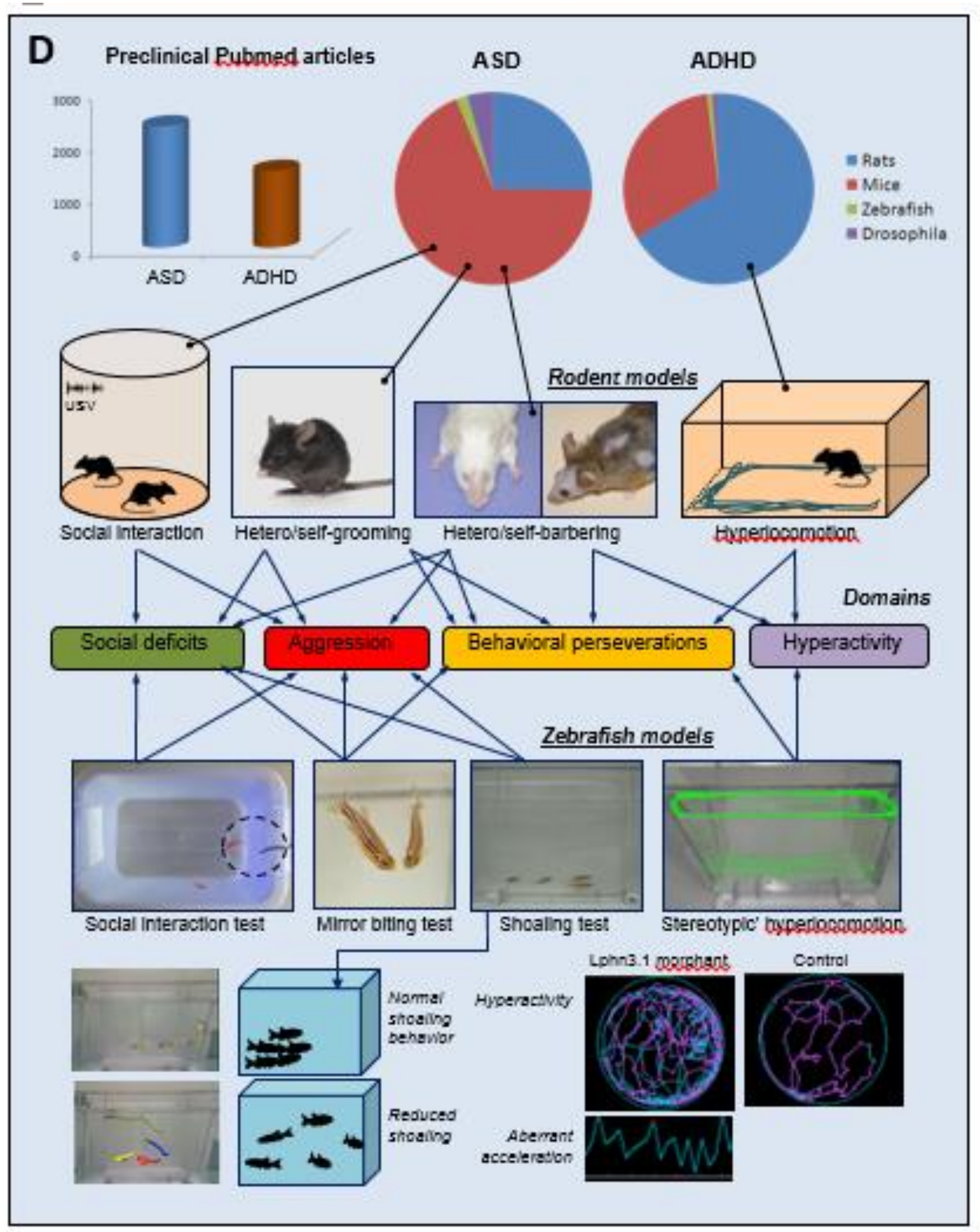


E

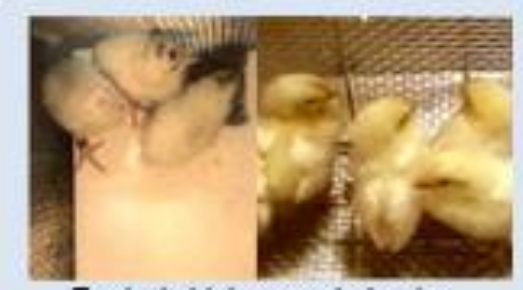

Typical chick group behavior

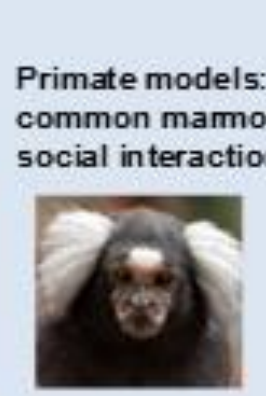
Distress $\longrightarrow$ vocalizations

$\downarrow$

Chick models: social isolation

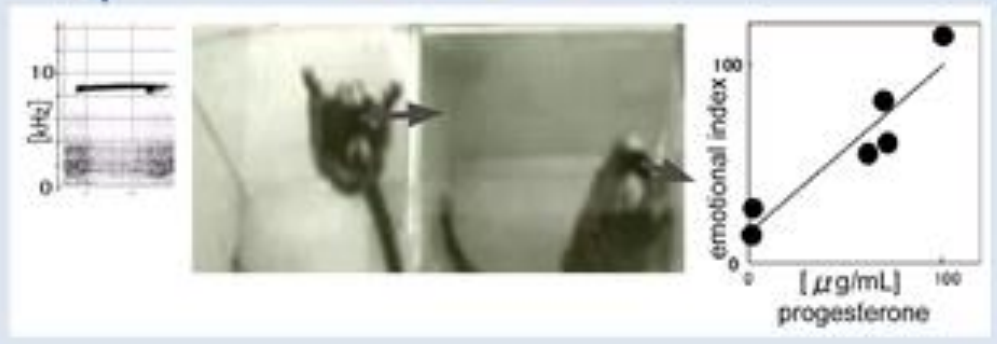

F Clinical models: infants and children
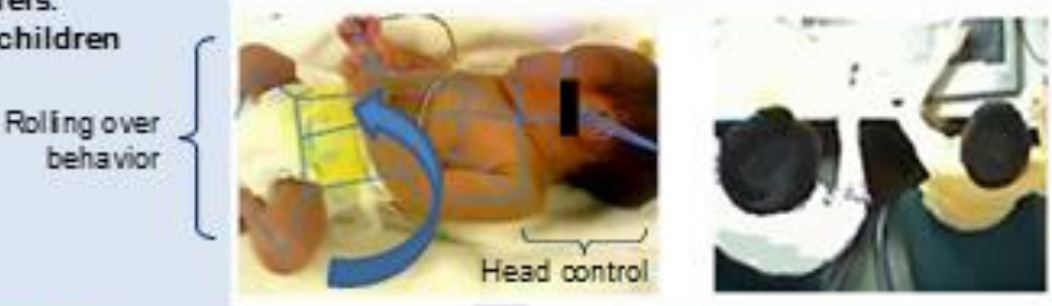

Parent area

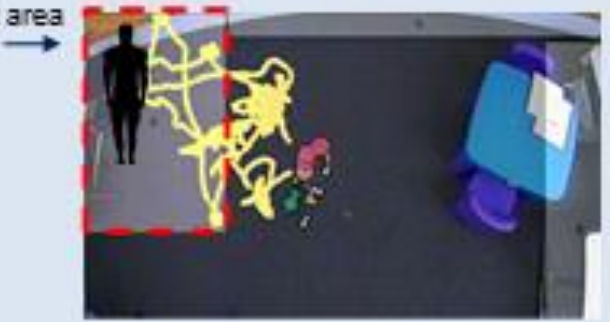

ASD child

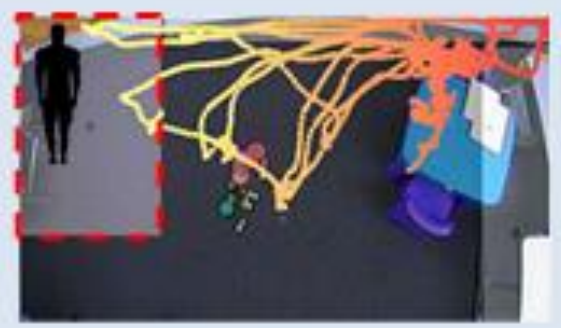

Normal child 
Figure 3. The concepts of Gene $x$ Environment interactions (GxE) and Gene-Environment correlations (G-E), as well as their potential implications for NDDs and their experimental animal models.
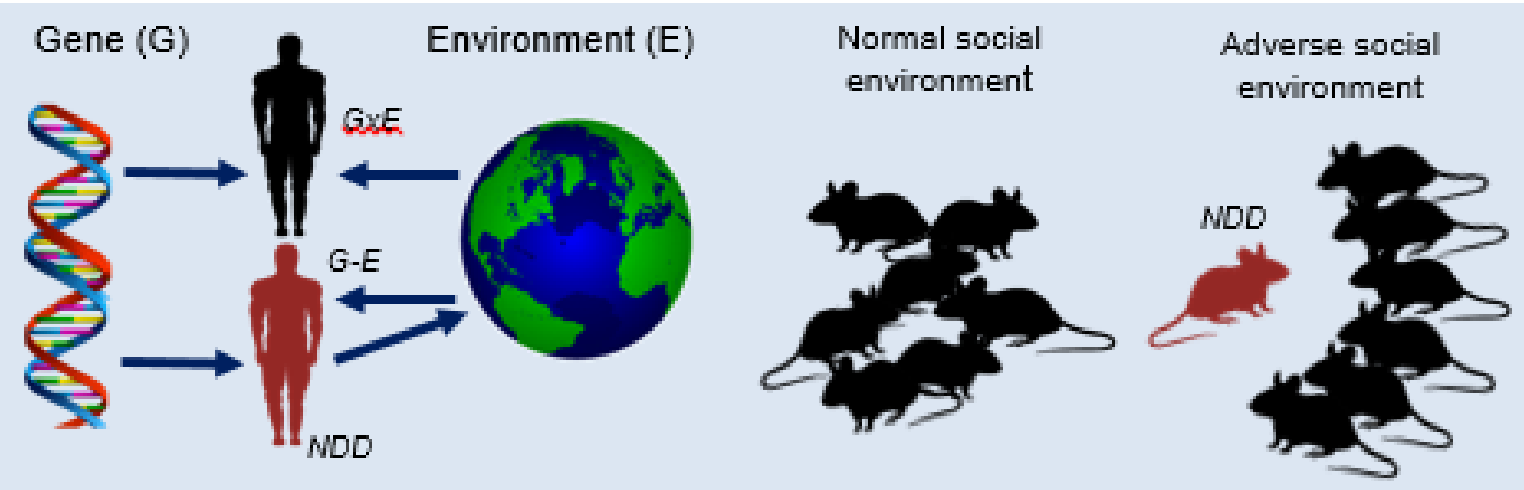
Figure 4. The proposed 'integrative' strategy for modeling of neurodevelopmental disorders (NDDs). NDDs usually consist of several 'core' symptoms (endophenotypes, e.g., A and B). Panel A shows 'early' experimental models of brain disorders that focus on targeting individual endophenotypes $\mathrm{A}$ or $\mathrm{B}$, and more recent complex models examining several endophenotype and their respective biomarkers in parallel $(\mathrm{A}+\mathrm{B}$ vs. A vs. B). As an example here, we use the mouse autism-like behaviors (endophenotype A - behavioral perseverations/self-grooming, endophenotype B - social deficit). In addition, we suggest that a network-like 'cloud' approach must be used to link disordered endophenotypes between themselves (i.e., A<->B vs. A+B vs. A vs. B), in order to identify their "interplay" genes and biomarkers, in addition to those 'unique' and 'shared' between them. For example, a disorder with stronger synchronization of endophenotypes A and B is likely to be more severe and treatment-resistant, as compared to a disease with similar 'amplitude' of endophenotypes, but the lack of their correlation. Panel B illustrates the importance of tracking the activity of all proposed genetic networks across ontogenesis, as different subgroups of genes (Aspecific, B-specific, and 'interplay' $\mathrm{A}<->\mathrm{B}$ genes may show distinct pattern of gene activity/expression (Y-axis) during neural development (X-axis). Circles represent the severity of phenotype expression (note that subtypes of severe NDDs may include cases of mild but tightly coordinated disordered endophenotypes, as well as strongly affected but relatively moderately coordinated/overlapping endophenotypes). 


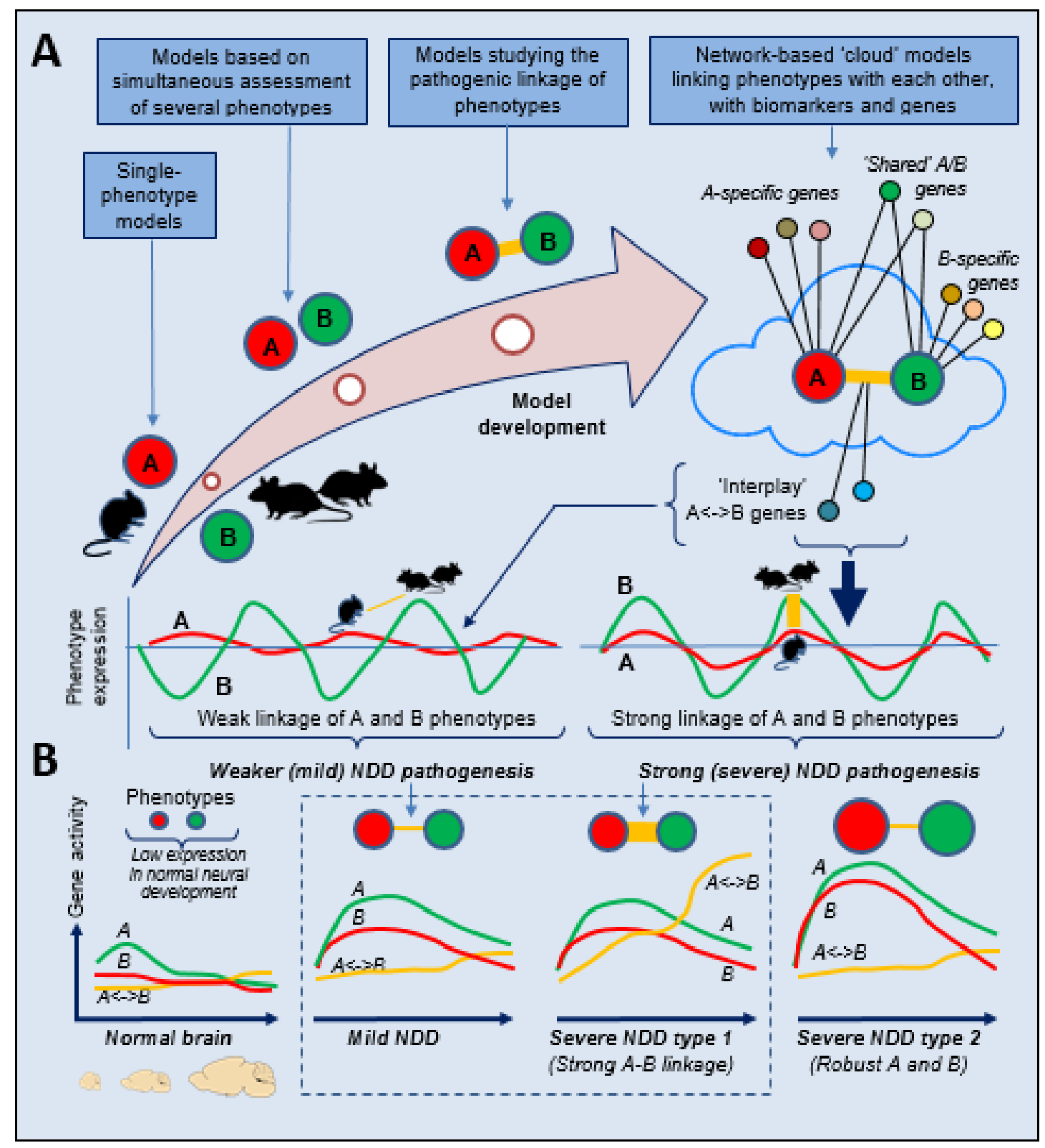


Table 1. Neurodevelopmental disorders currently listed in Diagnostic Statistical Manual (DSM5) (American Psychiatric et al., 2013), also see Table 2

\begin{tabular}{|c|c|}
\hline Disorders and their main symptoms & $\begin{array}{l}\text { Availability of } \\
\text { animal models }\end{array}$ \\
\hline $\begin{array}{l}\text { Intellectual Disabilities (ID) - impairment of mental functions in conceptual (language, reading, } \\
\text { writing, mathematics, memory, insight, knowledge, interpretation), social (empathy, compassion, } \\
\text { social judgment, communication and interaction skills, amicability, harmony) and practical } \\
\text { (personal care, school and/or occupational responsibilities and organization, financial management, } \\
\text { entertainment, hobby) aspects, including: Intellectual Disability (Intellectual Developmental } \\
\text { Disorder), Global Developmental Delay, Unspecified Intellectual Disability (Intellectual } \\
\text { Developmental Disorder) }\end{array}$ & + \\
\hline $\begin{array}{l}\text { Communication Disorders (CD) - difficulties in language, speech, phonetic fluency or social } \\
\text { communication, including: Language Disorder, Speech Sound Disorder, Childhood-Onset Fluency } \\
\text { Disorder (Stuttering), Social (Pragmatic) Communication Disorder, Unspecified Communication } \\
\text { Disorder }\end{array}$ & Not feasible \\
\hline $\begin{array}{l}\text { Autism Spectrum Disorder (ASD) - persistent reciprocal social deficits (communication and } \\
\text { interaction), and restricted, repetitive patterns of behavior, interests or thoughts }\end{array}$ & + \\
\hline $\begin{array}{l}\text { Attention-Deficit/Hyperactivity Disorder (ADHD) - a pattern of inattention and/or hyperactivity- } \\
\text { impulsivity, including: ADHD, Other Specified and Unspecified ADHD }\end{array}$ & + \\
\hline $\begin{array}{l}\text { Specific Learning Disorder - difficulties learning skills like reading, writing, spelling, mathematic } \\
\text { calculations, etc. }\end{array}$ & Not feasible \\
\hline $\begin{array}{l}\text { Motor Disorders (MD) - impairments of execution of coordinated motor skills, or repetitive } \\
\text { motor behaviors, including: Developmental Coordination Disorder, Stereotypic Movement } \\
\text { Disorder }\end{array}$ & + \\
\hline $\begin{array}{l}\text { Tic Disorders (TD) - habitual motor movements or vocalizations which are sudden, rapid, } \\
\text { recurrent and non-rhythmic, including: Tourette's Disorder, Persistent (Chronic) Motor or Vocal } \\
\text { Tic Disorder, Provisional Tic Disorder, Other Specified and Unspecified Tic Disorders }\end{array}$ & + \\
\hline Other Neurodevelopmental Disorders & ? \\
\hline
\end{tabular}


Table 2. Selected animal (rodent) models of neurodevelopmental disorders, abbreviations as in

Table 1 (also see Fig. 2 and Table 3) (Homberg et al., 2015).

\begin{tabular}{|lcclll|}
\hline \multicolumn{1}{|c}{ Animal (rodent) model } & $\begin{array}{c}\text { Ease to } \\
\text { perform }\end{array}$ & $\begin{array}{c}\text { Throug } \\
\text { hput }\end{array}$ & $\begin{array}{c}\text { Affected } \\
\text { domain/phenotype }\end{array}$ & \multicolumn{1}{c|}{ Clinical relevance } \\
\hline Social interaction test & ++ & + & Social deficit*/** & Social deficit in ASD \\
Social preference test & ++ & + & Social deficit* & Social deficit in ASD \\
Social recognition & + & + & Social deficit* & Social deficit in ASD, ID \\
Open field test & ++ & ++ & Hyperlocomotion* & Hyperactivity in ADHD \\
Homecage observation & ++ & + & Hyperlocomotion* & Hyperactivity in ADHD \\
Various memory tests & ++ & + & Cognitive deficits* & Cognitive deficits in ID and ADHD \\
Various attention tests & + & + & Attention deficits & Attention deficits in ADHD \\
Various impulsivity tests & + & + & Increased impulsivity & Increased impulsivity in ADHD \\
Self-grooming test & ++ & +++ & Increased grooming & Behavioral perseverations in ASD, TD \\
Hetero-grooming & ++ & + & Aberrant grooming & Social deficits in ASD, ID \\
Self-barbering test & ++ & + & Hair-loss (barbering) & Behavioral perseverations in ASD, TD \\
Hetero-barbering & ++ & + & Hair-loss (barbering) & Social deficits in ASD, ID \\
Open field test & ++ & +++ & Increased stereotypies* & Behavioral perseverations in ASD \\
Aggression test & ++ & + & Increased aggression** & Aggression in ID, ADHD \\
Marble burying test & +++ & +++ & Increased burying & Behavioral perseverations in ASD \\
Homecage observation & ++ & + & Increased stereotypies* & Behavioral perseverations in ASD \\
Startle test & +++ & +++ & Aberrant startle* & Altered cognition in ADHD and ID \\
Ultrasonic vocalizations & + & ++ & Aberrant vocalization & Social deficits in ASD, ID or CD \\
\hline
\end{tabular}

* denotes the availability of similar tests in alternative model organisms, such as zebrafish (Fig. 2)

** also see shoaling test and mirror biting test in zebrafish (Green et al., 2012; Miller et al., 2013) (Fig. 2D) 
Table 3. Tests used to measure the neural development and behavior of young rodents (Homberg et al., 2015).

\begin{tabular}{|c|c|c|c|}
\hline Tests & System measured & Age of testing & Referen-ces \\
\hline \multicolumn{4}{|l|}{ Simple Reflexes } \\
\hline Pupillary constriction & Sensorimotor & $\begin{array}{l}\text { PND12 to } \\
\text { appearance }\end{array}$ & (Crofton, 1992) \\
\hline Salivation & Sensorimotor & $\begin{array}{l}\text { PND2 to } \\
\text { appearance }\end{array}$ & (Crofton, 1992) \\
\hline Lacrimation & Sensorimotor & $\begin{array}{l}\text { PND2 to } \\
\text { appearance }\end{array}$ & (Crofton, 1992) \\
\hline Acoustic startle & Auditory, Motor & $\begin{array}{l}\text { PND6 to } \\
\text { appearance }\end{array}$ & (Fox, 1965) \\
\hline Forelimb grasp reflex & Somatic, Motor & $\begin{array}{l}\text { PND2 to } \\
\text { appearance }\end{array}$ & (Blaney et al., 2013; Fox, 1965) \\
\hline Hindlimb grasp reflex & Somatic, Motor & $\begin{array}{l}\text { PND2 to } \\
\text { appearance }\end{array}$ & $\begin{array}{l}\text { (Amendola et al., 2004; Blaney et al., } \\
\text { 2013; Fox, 1965) }\end{array}$ \\
\hline $\begin{array}{l}\text { Loss of crossed- } \\
\text { extensor reflex }\end{array}$ & Somatic, Motor & $\begin{array}{l}\text { PND2 to } \\
\text { disappearance }\end{array}$ & (Blaney et al., 2013; Fox, 1965) \\
\hline $\begin{array}{l}\text { Loss of rooting } \\
\text { response }\end{array}$ & Somatic, Motor & $\begin{array}{l}\text { PND2 to } \\
\text { disappearance }\end{array}$ & (Fox, 1965; Roubertoux et al., 1987) \\
\hline Vibrissae response & Somatic, Motor & $\begin{array}{l}\text { PND2 to } \\
\text { appearance }\end{array}$ & $\begin{array}{l}\text { (Amendola et al., 2004; Blaney et al., } \\
\text { 2013; Fox, 1965) }\end{array}$ \\
\hline \multicolumn{4}{|l|}{ Sensory and motor } \\
\hline Reflex modification & $\begin{array}{l}\text { Visual, Auditory, } \\
\text { Olfactory, Somatic }\end{array}$ & PND 14-onwards & (Wecker et al., 1985) \\
\hline Cliff avoidance & $\begin{array}{l}\text { Visual: depth } \\
\text { perception }\end{array}$ & PND 14-onwards & (Fox, 1965) \\
\hline Visual placing test & $\begin{array}{l}\text { Visual, motor } \\
\text { coordination }\end{array}$ & PND14-onwards & (Pinto and Enroth-Cugell, 2000) \\
\hline $\begin{array}{l}\text { Olfactory } \\
\text { discrimination }\end{array}$ & Olfaction & After weaning & (Brown and Willner, 1983) \\
\hline Swimming test & $\begin{array}{l}\text { Vestibular, } \\
\text { Neuromotor } \\
\text { coordination }\end{array}$ & After weaning & (Kalueff et al., 2004) \\
\hline
\end{tabular}




\begin{tabular}{|c|c|c|c|}
\hline Negative geotaxis & $\begin{array}{l}\text { Vestibular, } \\
\text { Neuromotor } \\
\text { coordination }\end{array}$ & PND2-onwards & (Blaney et al., 2013; Fox, 1965) \\
\hline Surface righting & $\begin{array}{l}\text { Vestibular, } \\
\text { Neuromotor } \\
\text { coordination }\end{array}$ & PND 2-onwards & (Amendola et al., 2004; Fox, 1965) \\
\hline Mid-air righting & $\begin{array}{l}\text { Vestibular, } \\
\text { Neuromotor } \\
\text { coordination }\end{array}$ & PND2-onwards & (Fox, 1965) \\
\hline Hindlimb splay & $\begin{array}{l}\text { Vestibular, } \\
\text { Neuromotor } \\
\text { coordination }\end{array}$ & PND2-onwards & (Broxup et al., 1989; Moser et al., 1988) \\
\hline Gait analysis & $\begin{array}{l}\text { Neuromotor } \\
\text { coordination }\end{array}$ & After weaning & (Wooley et al., 2005) \\
\hline Rotarod, accelerod & $\begin{array}{l}\text { Neuromotor } \\
\text { coordination }\end{array}$ & After weaning & (Van Raamsdonk et al., 2005) \\
\hline Horizontal rod test & $\begin{array}{l}\text { Vestibular, } \\
\text { Neuromotor } \\
\text { coordination }\end{array}$ & After weaning & (Kalueff et al., 2008a) \\
\hline $\begin{array}{l}\text { Forelimb grip strength } \\
\text { test }\end{array}$ & $\begin{array}{l}\text { Neuromotor } \\
\text { coordination, } \\
\text { muscle strength }\end{array}$ & PND2-onwards & (Blaney et al., 2013) \\
\hline Nest building test & $\begin{array}{l}\text { Neuromotor } \\
\text { coordination }\end{array}$ & After weaning & (Kalueff et al., 2007b) \\
\hline Rope climbing test & $\begin{array}{l}\text { Neuromotor } \\
\text { coordination, } \\
\text { muscle strength }\end{array}$ & After weaning & (Kalueff et al., 2007b) \\
\hline Vertical screen test & $\begin{array}{l}\text { Neuromotor } \\
\text { coordination, } \\
\text { muscle strength }\end{array}$ & After weaning & (Kalueff et al., 2004) \\
\hline Self-grooming test & $\begin{array}{l}\text { Neuromotor } \\
\text { coordination, } \\
\text { muscle strength }\end{array}$ & After weaning & (Kalueff and Tuohimaa, 2004a, 2005a) \\
\hline Open Field & Locomotor activity & PND12-onwards & (Alleva et al., 1985; Blaney et al., 2013) \\
\hline
\end{tabular}




\begin{tabular}{|c|c|c|c|}
\hline \multicolumn{4}{|l|}{ Cognitive tests } \\
\hline $\begin{array}{l}\text { Olfactory } \\
\text { conditioning }\end{array}$ & $\begin{array}{l}\text { Learning and } \\
\text { memory }\end{array}$ & PND6 onwards & (Sullivan and Wilson, 1995) \\
\hline Neonatal T-maze & $\begin{array}{l}\text { Learning and } \\
\text { memory }\end{array}$ & PND9-onwards & (Nagy et al., 1976) \\
\hline Hebb Williams Maze & $\begin{array}{l}\text { Learning and } \\
\text { memory }\end{array}$ & After weaning & $\begin{array}{l}\text { (Hebb and Williams, 1946; Pritchett and } \\
\text { Mulder, 2004) }\end{array}$ \\
\hline Morris water maze & $\begin{array}{l}\text { Learning and } \\
\text { memory }\end{array}$ & After weaning & (Morris, 1984) \\
\hline Passive avoidance test & $\begin{array}{l}\text { Learning and } \\
\text { memory }\end{array}$ & After weaning & (Cuomo et al., 1996) \\
\hline Active avoidance test & $\begin{array}{l}\text { Learning and } \\
\text { memory }\end{array}$ & After weaning & (McNamara et al., 1977) \\
\hline $\begin{array}{l}\text { Operant conditioning } \\
\text { schedules }\end{array}$ & $\begin{array}{l}\text { Learning and } \\
\text { memory }\end{array}$ & After weaning & (Cuomo et al., 1996) \\
\hline Homing test & $\begin{array}{l}\text { Learning and } \\
\text { memory }\end{array}$ & PND14-onwards & (Alleva et al., 1985; Fox, 1965) \\
\hline $\begin{array}{l}\text { Object recognition } \\
\text { test }\end{array}$ & $\begin{array}{l}\text { Learning and } \\
\text { memory }\end{array}$ & PND22-onwards & (Blaney et al., 2013) \\
\hline \multicolumn{4}{|l|}{ Social/ Emotional } \\
\hline $\begin{array}{l}\text { Ultrasonic } \\
\text { vocalization }\end{array}$ & Anxiety, sociability & PND2-onwards & $\begin{array}{l}\text { (Bolivar and Brown, 1994; Scattoni et } \\
\text { al., 2009) }\end{array}$ \\
\hline Elevated plus maze & Anxiety & After weaning & (Cuomo et al., 1996) \\
\hline $\begin{array}{l}\text { Black and white } \\
\text { transition test }\end{array}$ & Anxiety & After weaning & (Crawley, 1981) \\
\hline Social interaction test & Anxiety, sociability & After weaning & (Crawley, 1981) \\
\hline $\begin{array}{l}\text { Self-grooming } \\
\text { analysis }\end{array}$ & $\begin{array}{l}\text { Anxiety, repetitive } \\
\text { behavior }\end{array}$ & After weaning & $\begin{array}{l}\text { (Kalueff et al., 2007a; Kalueff and } \\
\text { Tuohimaa, 2004b) }\end{array}$ \\
\hline Suok test & $\begin{array}{l}\text { Anxiety, } \\
\text { motorisensory } \\
\text { integration }\end{array}$ & After weaning & $\begin{array}{l}\text { (Kalueff et al., 2008a; Kalueff and } \\
\text { Tuohimaa, 2005b) }\end{array}$ \\
\hline Social preference test & Sociability & After weaning & $\begin{array}{l}\text { (Ricceri et al., 2007; Silverman and } \\
\text { Crawley, 2014) }\end{array}$ \\
\hline
\end{tabular}




\section{Bibliography:}

2015. Autism Spectrum Disorder Data and Statistics. Center for Disease Control.

(APA), A.P.A., 2013. Diagnostic and statistical manual of mental disorders (5th ed.). APA, Washington, D.C. Alleva, E., Laviola, G., Tirelli, E., Bignami, G., 1985. Short-, medium-, and long-term effects of prenatal oxazepam on neurobehavioural development of mice. Psychopharmacology (Berl) 87, 434-441.

Altamura, C., Dell'Acqua, M.L., Moessner, R., Murphy, D.L., Lesch, K.P., Persico, A.M., 2007. Altered neocortical cell density and layer thickness in serotonin transporter knockout mice: a quantitation study. Cerebral cortex 17, 1394-1401.

Amendola, J., Verrier, B., Roubertoux, P., Durand, J., 2004. Altered sensorimotor development in a transgenic mouse model of amyotrophic lateral sclerosis. Eur J Neurosci 20, 2822-2826.

American Psychiatric, A., American Psychiatric, A., Force, D.S.M.T., 2013. Diagnostic and statistical manual of mental disorders : DSM-5.

Amodeo, D.A., Yi, J., Sweeney, J.A., Ragozzino, M.E., 2014. Oxotremorine treatment reduces repetitive behaviors in BTBR T+ tf/J mice. Frontiers in synaptic neuroscience 6, 17.

Antrop, I., Roeyers, H., Van Oost, P., Buysse, A., 2000. Stimulation seeking and hyperactivity in children with ADHD. Attention Deficit Hyperactivity Disorder. Journal of child psychology and psychiatry, and allied disciplines 41, 225-231.

Arcos-Burgos, M., Jain, M., Acosta, M.T., Shively, S., Stanescu, H., Wallis, D., Domene, S., Velez, J.I., Karkera, J.D., Balog, J., Berg, K., Kleta, R., Gahl, W.A., Roessler, E., Long, R., Lie, J., Pineda, D., Londono, A.C., Palacio, J.D., Arbelaez, A., Lopera, F., Elia, J., Hakonarson, H., Johansson, S., Knappskog, P.M., Haavik, J., Ribases, M., Cormand, B., Bayes, M., Casas, M., Ramos-Quiroga, J.A., Hervas, A., Maher, B.S., Faraone, S.V., Seitz, C., Freitag, C.M., Palmason, H., Meyer, J., Romanos, M., Walitza, S., Hemminger, U., Warnke, A., Romanos, J., Renner, T., Jacob, C., Lesch, K.P., Swanson, J., Vortmeyer, A., Bailey-Wilson, J.E., Castellanos, F.X., Muenke, M., 2010. A common variant of the latrophilin 3 gene, LPHN3, confers susceptibility to ADHD and predicts effectiveness of stimulant medication. Molecular psychiatry 15, 1053-1066.

Argyropoulos, A., Gilby, K.L., Hill-Yardin, E.L., 2013. Studying autism in rodent models: reconciling endophenotypes with comorbidities. Frontiers in human neuroscience 7, 417.

Bader, P.L., Faizi, M., Kim, L.H., Owen, S.F., Tadross, M.R., Alfa, R.W., Bett, G.C., Tsien, R.W., Rasmusson, R.L., Shamloo, M., 2011. Mouse model of Timothy syndrome recapitulates triad of autistic traits. Proceedings of the National Academy of Sciences of the United States of America 108, 15432-15437.

Bale, T.L., Baram, T.Z., Brown, A.S., Goldstein, J.M., Insel, T.R., McCarthy, M.M., Nemeroff, C.B., Reyes, T.M., Simerly, R.B., Susser, E.S., Nestler, E.J., 2010. Early life programming and neurodevelopmental disorders. Biol Psychiatry 68, 314-319.

Barr, A.M., Lehmann-Masten, V., Paulus, M., Gainetdinov, R.R., Caron, M.G., Geyer, M.A., 2004. The selective serotonin-2A receptor antagonist M100907 reverses behavioral deficits in dopamine transporter knockout mice. Neuropsychopharmacology 29, 221-228.

Bergner, C.L., Smolinsky, A.N., Hart, P.C., Dufour, B.D., Egan, R.J., Laporte, J.L., Kalueff, A.V., 2010. Mouse models for studying depression-like states and antidepressant drugs. Methods Mol Biol 602, 267-282.

Berridge, K.C., Aldridge, J.W., Houchard, K.R., Zhuang, X., 2005. Sequential super-stereotypy of an instinctive fixed action pattern in hyper-dopaminergic mutant mice: a model of obsessive compulsive disorder and Tourette's. BMC biology 3, 4.

Bishop, S.L., Lahvis, G.P., 2011. The autism diagnosis in translation: shared affect in children and mouse models of ASD. Autism Res 4, 317-335.

Blaney, C.E., Gunn, R.K., Stover, K.R., Brown, R.E., 2013. Maternal genotype influences behavioral development of 3xTg-AD mouse pups. Behav Brain Res 252, 40-48.

Blaser, R.E., Chadwick, L., McGinnis, G.C., 2009. Behavioral measures of anxiety in zebrafish (Danio rerio). Behavioural brain research.

Blin, M., Norton, W., Bally-Cuif, L., Vernier, P., 2008. NR4A2 controls the differentiation of selective dopaminergic nuclei in the zebrafish brain. Molecular and cellular neurosciences 39, 592-604. 
Bloom, B., Jones, L., Freeman, G., 2013. Summary Health Statistics for U.S. Children: National Health Interview Survey 2012. US Government Printing Office.

Blundell, J., Tabuchi, K., Bolliger, M.F., Blaiss, C.A., Brose, N., Liu, X., Sudhof, T.C., Powell, C.M., 2009. Increased anxiety-like behavior in mice lacking the inhibitory synapse cell adhesion molecule neuroligin 2. Genes, brain, and behavior 8, 114-126.

Bolivar, V.J., Brown, R.E., 1994. The ontogeny of ultrasonic vocalizations and other behaviors in male jimpy (jp/Y) mice and their normal male littermates. Dev Psychobiol 27, 101-110.

Bonnin, A., Levitt, P., 2011. Fetal, maternal, and placental sources of serotonin and new implications for developmental programming of the brain. Neuroscience 197, 1-7.

Boyer, B.E., Geurts, H.M., Prins, P.J., Van der Oord, S., 2015. One-year follow-up of two novel CBTs for adolescents with ADHD. Eur Child Adolesc Psychiatry.

Bozdagi, O., Sakurai, T., Papapetrou, D., Wang, X., Dickstein, D.L., Takahashi, N., Kajiwara, Y., Yang, M., Katz, A.M., Scattoni, M.L., Harris, M.J., Saxena, R., Silverman, J.L., Crawley, J.N., Zhou, Q., Hof, P.R., Buxbaum, J.D., 2010. Haploinsufficiency of the autism-associated Shank3 gene leads to deficits in synaptic function, social interaction, and social communication. Molecular autism 1, 15.

Branchi, I., D'Andrea, I., Cirulli, F., Lipp, H.P., Alleva, E., 2010. Shaping brain development: mouse communal nesting blunts adult neuroendocrine and behavioral response to social stress and modifies chronic antidepressant treatment outcome. Psychoneuroendocrinology 35, 743-751.

Branchi, I., Ricceri, L., 2002. Transgenic and knock-out mouse pups: the growing need for behavioral analysis. Genes, brain, and behavior 1, 135-141.

Brodkin, J., Frank, D., Grippo, R., Hausfater, M., Gulinello, M., Achterholt, N., Gutzen, C., 2014. Validation and implementation of a novel high-throughput behavioral phenotyping instrument for mice. Journal of neuroscience methods 224, 48-57.

Bronfeld, M., Israelashvili, M., Bar-Gad, I., 2013. Pharmacological animal models of Tourette syndrome. Neurosci Biobehav Rev 37, 1101-1119.

Brophy, K., Hawi, Z., Kirley, A., Fitzgerald, M., Gill, M., 2002. Synaptosomal-associated protein 25 (SNAP-25) and attention deficit hyperactivity disorder (ADHD): evidence of linkage and association in the Irish population. Molecular psychiatry 7, 913-917.

Brown, R.E., Willner, J.A., 1983. Establishing an "affective scale" for odor preferences of infant rats. Behav Neural Biol 38, 251-260.

Broxup, B., Robinson, K., Losos, G., Beyrouty, P., 1989. Correlation between behavioral and pathological changes in the evaluation of neurotoxicity. Toxicol Appl Pharmacol 101, 510-520.

Bruno, K.J., Freet, C.S., Twining, R.C., Egami, K., Grigson, P.S., Hess, E.J., 2007. Abnormal latent inhibition and impulsivity in coloboma mice, a model of ADHD. Neurobiology of disease 25, 206-216.

Buckley, P.F., Miller, B.J., Lehrer, D.S., Castle, D.J., 2009. Psychiatric comorbidities and schizophrenia. Schizophrenia Bulletin 35, 383-402.

Buelke-Sam, J., Kimmel, C.A., 1979. Development and standardization of screening methods for behavioral teratology. Teratology 20, 17-29.

Burket, J.A., Benson, A.D., Tang, A.H., Deutsch, S.I., 2013. D-Cycloserine improves sociability in the BTBR T+ Itpr3tf/J mouse model of autism spectrum disorders with altered Ras/Raf/ERK1/2 signaling. Brain research bulletin 96, 62-70.

Butcher, R.E., 1976. Behavioral testing as a method for assessing risk. Environ Health Perspect 18, 75-78. Cachat, J.M., Canavello, P.R., Elegante, M.F., Bartels, B.K., Elkhayat, S.I., Hart, P.C., Tien, A.K., Tien, D.H., Beeson, E., Mohnot, S., 2011. Modeling stress and anxiety in zebrafish, Zebrafish models in neurobehavioral research. Springer, pp. 73-88.

Cases, O., Vitalis, T., Seif, I., De Maeyer, E., Sotelo, C., Gaspar, P., 1996. Lack of barrels in the somatosensory cortex of monoamine oxidase A-deficient mice: role of a serotonin excess during the critical period. Neuron 16, 297-307.

Casey, B.J., Craddock, N., Cuthbert, B.N., Hyman, S.E., Lee, F.S., Ressler, K.J., 2013. DSM-5 and RDoC: progress in psychiatry research? Nature reviews. Neuroscience 14, 810-814. 
Castellan Baldan, L., Williams, K.A., Gallezot, J.D., Pogorelov, V., Rapanelli, M., Crowley, M., Anderson, G.M., Loring, E., Gorczyca, R., Billingslea, E., Wasylink, S., Panza, K.E., Ercan-Sencicek, A.G., Krusong, K., Leventhal, B.L., Ohtsu, H., Bloch, M.H., Hughes, Z.A., Krystal, J.H., Mayes, L., de Araujo, I., Ding, Y.S., State, M.W., Pittenger, C., 2014. Histidine decarboxylase deficiency causes tourette syndrome: parallel findings in humans and mice. Neuron 81, 77-90.

Chameau, P., Inta, D., Vitalis, T., Monyer, H., Wadman, W.J., van Hooft, J.A., 2009. The N-terminal region of reelin regulates postnatal dendritic maturation of cortical pyramidal neurons. Proceedings of the National Academy of Sciences of the United States of America 106, 7227-7232.

Chemelli, R.M., Willie, J.T., Sinton, C.M., Elmquist, J.K., Scammell, T., Lee, C., Richardson, J.A., Williams, S.C., Xiong, Y., Kisanuki, Y., Fitch, T.E., Nakazato, M., Hammer, R.E., Saper, C.B., Yanagisawa, M., 1999. Narcolepsy in orexin knockout mice: molecular genetics of sleep regulation. Cell 98, 437-451.

Chen, T.H., Wang, Y.H., Wu, Y.H., 2011. Developmental exposures to ethanol or dimethylsulfoxide at low concentrations alter locomotor activity in larval zebrafish: implications for behavioral toxicity bioassays. Aquatic toxicology (Amsterdam, Netherlands) 102, 162-166.

Chen, X., Ye, R., Gargus, J.J., Blakely, R.D., Dobrenis, K., Sze, J.Y., 2015. Disruption of Transient Serotonin Accumulation by Non-Serotonin-Producing Neurons Impairs Cortical Map Development. Cell reports.

Chen, Y.H., Rodgers, J., McConachie, H., 2009. Restricted and repetitive behaviours, sensory processing and cognitive style in children with autism spectrum disorders. Journal of autism and developmental disorders 39 , 635-642.

Colacicco, G., Welzl, H., Lipp, H.P., Wurbel, H., 2002. Attentional set-shifting in mice: modification of a rat paradigm, and evidence for strain-dependent variation. Behav Brain Res 132, 95-102.

Cools, R., Roberts, A.C., Robbins, T.W., 2008. Serotoninergic regulation of emotional and behavioural control processes. Trends in cognitive sciences 12, 31-40.

Corkum, P., Tannock, R., Moldofsky, H., Hogg-Johnson, S., Humphries, T., 2001. Actigraphy and parental ratings of sleep in children with attention-deficit/hyperactivity disorder (ADHD). Sleep 24, 303-312.

Courtet, P., Gottesman, II, Jollant, F., Gould, T.D., 2011. The neuroscience of suicidal behaviors: what can we expect from endophenotype strategies? Translational psychiatry 1.

Crawley, J.N., 1981. Neuropharmacologic specificity of a simple animal model for the behavioral actions of benzodiazepines. Pharmacol Biochem Behav 15, 695-699.

Crawley, J.N., 2004. Designing mouse behavioral tasks relevant to autistic-like behaviors. Mental retardation and developmental disabilities research reviews 10, 248-258.

Crawley, J.N., 2007. Mouse behavioral assays relevant to the symptoms of autism. Brain pathology (Zurich, Switzerland) $17,448-459$.

Creese, I., Iversen, S.D., 1975. The pharmacological and anatomical substrates of the amphetamine response in the rat. Brain research 83, 419-436.

Crofton, K.M., 1992. Reflex modification and the assessment of sensory dysfunction. TARGET ORGAN TOXICOLOGY SERIES. 1992.

Cromwell, H.C., Berridge, K.C., Drago, J., Levine, M.S., 1998. Action sequencing is impaired in D1A-deficient mutant mice. The European journal of neuroscience 10, 2426-2432.

Crossley, N.A., Mechelli, A., Scott, J., Carletti, F., Fox, P.T., McGuire, P., Bullmore, E.T., 2014. The hubs of the human connectome are generally implicated in the analomy of brain disorders. Brain, 1-14.

Cryan, J.F., Holmes, A., 2005. The ascent of mouse: advances in modelling human depression and anxiety. Nat Rev Drug Discov 4, 775-790.

Cryan, J.F., Slattery, D.A., 2007. Animal models of mood disorders: Recent developments. Current opinion in psychiatry 20, 1-7.

Cuomo, V., De Salvia, M.A., Petruzzi, S., Alleva, E., 1996. Appropriate end points for the characterization of behavioral changes in developmental toxicology. Environ Health Perspect 104 Suppl 2, 307-315.

Cuthbert, B.N., Insel, T.R., 2010. Toward new approaches to psychotic disorders: the NIMH Research Domain Criteria project. Schizophrenia bulletin 36, 1061-1062. 
Davids, E., Zhang, K., Tarazi, F.I., Baldessarini, R.J., 2003. Animal models of attention-deficit hyperactivity disorder. Brain Res Brain Res Rev 42, 1-21.

De Filippis, B., Ricceri, L., Laviola, G., 2010. Early postnatal behavioral changes in the Mecp2-308 truncation mouse model of Rett syndrome. Genes, brain, and behavior 9, 213-223.

De Villiers, A.S., Russell, V.A., Sagvolden, T., Searson, A., Jaffer, A., Taljaard, J.J., 1995. Alpha 2-adrenoceptor mediated inhibition of $[3 \mathrm{H}]$ dopamine release from nucleus accumbens slices and monoamine levels in a rat model for attention-deficit hyperactivity disorder. Neurochemical research 20, 427-433.

Deakin, J.F., Graeff, F.G., 1991. 5-HT and mechanisms of defence. Journal of psychopharmacology 5, 305-315. DeLorey, T.M., Handforth, A., Anagnostaras, S.G., Homanics, G.E., Minassian, B.A., Asatourian, A., Fanselow, M.S., Delgado-Escueta, A., Ellison, G.D., Olsen, R.W., 1998. Mice lacking the beta3 subunit of the GABAA receptor have the epilepsy phenotype and many of the behavioral characteristics of Angelman syndrome. J Neurosci 18, 8505-8514.

Denys, D., de Vries, F., Cath, D., Figee, M., Vulink, N., Veltman, D.J., van der Doef, T.F., Boellaard, R., Westenberg, H., van Balkom, A., Lammertsma, A.A., van Berckel, B.N., 2013. Dopaminergic activity in Tourette syndrome and obsessive-compulsive disorder. European neuropsychopharmacology : the journal of the European College of Neuropsychopharmacology 23, 1423-1431.

Deoni, S.C., Zinkstok, J.R., Daly, E., Ecker, C., Consortium, M.A., Williams, S.C., Murphy, D.G., 2015. Whitematter relaxation time and myelin water fraction differences in young adults with autism. Psychological medicine 45, 795-805.

Ding, B., 2015. Gene expression in maturing neurons: regulatory mechanisms and related neurodevelopmental disorders. Sheng li xue bao : [Acta physiologica Sinica] 67, 113-133.

Ditzen, C., Tang, N., Jastorff, A.M., Teplytska, L., Yassouridis, A., Maccarrone, G., Uhr, M., Bronisch, T., Miller, C.A., Holsboer, F., Turck, C.W., 2012. Cerebrospinal fluid biomarkers for major depression confirm relevance of associated pathophysiology. Neuropsychopharmacology : official publication of the American College of Neuropsychopharmacology 37, 1013-1025.

Dufour, B.D., Adeola, O., Cheng, H.W., Donkin, S.S., Klein, J.D., Pajor, E.A., Garner, J.P., 2010. Nutritional upregulation of serotonin paradoxically induces compulsive behavior. Nutritional neuroscience 13, 256-264. Duncan, L.E., Pollastri, A.R., Smoller, J.W., 2014. Mind the gap: why many geneticists and psychological scientists have discrepant views about gene-environment interaction (GxE) research. Am Psychol 69, 249268.

Dykens, E.M., 2015. Family adjustment and interventions in neurodevelopmental disorders. Current opinion in psychiatry 28, 121-126.

Ehret, G., 2005. Infant rodent ultrasounds -- a gate to the understanding of sound communication. Behavior genetics 35, 19-29.

Elmazar, M.M., Sullivan, F.M., 1981. Effect of prenatal phenytoin administration on postnatal development of the rat: a behavioral teratology study. Teratology 24, 115-124.

Elsabbagh, M., Gliga, T., Pickles, A., Hudry, K., Charman, T., Johnson, M.H., 2013. The development of face orienting mechanisms in infants at-risk for autism. Behavioural brain research 251, 147-154.

Elwood, R.W., Keeling, F., 1982. Temporal organization of ultrasonic vocalizations in infant mice.

Developmental psychobiology 15, 221-227.

Ey, E., Torquet, N., Le Sourd, A.M., Leblond, C.S., Boeckers, T.M., Faure, P., Bourgeron, T., 2013. The Autism ProSAP1/Shank2 mouse model displays quantitative and structural abnormalities in ultrasonic vocalisations. Behavioural brain research 256, 677-689.

Fassio, A., Raimondi, A., Lignani, G., Benfenati, F., Baldelli, P., 2011. Synapsins: from synapse to network hyperexcitability and epilepsy. Semin Cell Dev Biol 22, 408-415.

Felling, R.J., Singer, H.S., 2011. Neurobiology of tourette syndrome: current status and need for further investigation. The Journal of neuroscience : the official journal of the Society for Neuroscience 31, 1238712395.

Feyder, M., Karlsson, R.M., Mathur, P., Lyman, M., Bock, R., Momenan, R., Munasinghe, J., Scattoni, M.L., Ihne, J., Camp, M., Graybeal, C., Strathdee, D., Begg, A., Alvarez, V.A., Kirsch, P., Rietschel, M., Cichon, S., 
Walter, H., Meyer-Lindenberg, A., Grant, S.G., Holmes, A., 2010. Association of mouse Dlg4 (PSD-95) gene deletion and human DLG4 gene variation with phenotypes relevant to autism spectrum disorders and Williams' syndrome. The American journal of psychiatry 167, 1508-1517.

Filiou, M.D., Zhang, Y., Teplytska, L., Reckow, S., Gormanns, P., Maccarrone, G., Frank, E., Kessler, M.S., Hambsch, B., Nussbaumer, M., Bunck, M., Ludwig, T., Yassouridis, A., Holsboer, F., Landgraf, R., Turck, C.W., 2011. Proteomics and metabolomics analysis of a trait anxiety mouse model reveals divergent mitochondrial pathways. Biological psychiatry 70, 1074-1082.

Fox, M., 1965. Neuro-ontogeny of neuromuscular mutant mice. Journal of Heredity 56, 55-60.

Frederick, A.L., Stanwood, G.D., 2009. Drugs, Biogenic Amine Targets and the Developing Brain.

Developmental neuroscience 31, 7-22.

Frith, U., Morton, J., Leslie, A.M., 1991. The cognitive basis of a biological disorder: autism. Trends Neurosci 14, 433-438.

Gainetdinov, R.R., Jones, S.R., Fumagalli, F., Wightman, R.M., Caron, M.G., 1998. Re-evaluation of the role of the dopamine transporter in dopamine system homeostasis. Brain Res Brain Res Rev 26, 148-153.

Gandal, M.J., Sisti, J., Klook, K., Ortinski, P.I., Leitman, V., Liang, Y., Thieu, T., Anderson, R., Pierce, R.C., Jonak, G., Gur, R.E., Carlson, G., Siegel, S.J., 2012. GABAB-mediated rescue of altered excitatory-inhibitory balance, gamma synchrony and behavioral deficits following constitutive NMDAR-hypofunction. Translational psychiatry 2, e142.

Garner, J.P., Thogerson, C.M., Dufour, B.D., Wurbel, H., Murray, J.D., Mench, J.A., 2011. Reverse-translational biomarker validation of Abnormal Repetitive Behaviors in mice: an illustration of the 4P's modeling approach. Behavioural brain research 219, 189-196.

Garner, J.P., Thogerson, C.M., Wurbel, H., Murray, J.D., Mench, J.A., 2006. Animal neuropsychology: validation of the Intra-Dimensional Extra-Dimensional set shifting task for mice. Behav Brain Res 173, 53-61. Garner, J.P., Weisker, S.M., Dufour, B., Mench, J.A., 2004. Barbering (fur and whisker trimming) by laboratory mice as a model of human trichotillomania and obsessive-compulsive spectrum disorders. Comparative medicine 54, 216-224.

Gaspar, P., Cases, O., Maroteaux, L., 2003. The developmental role of serotonin: news from mouse molecular genetics. Nature reviews. Neuroscience 4, 1002-1012.

Gilby, K.L., O'Brien, T.J., 2013. Epilepsy, autism, and neurodevelopment: kindling a shared vulnerability? Epilepsy Behav 26, 370-374.

Gillott, A., Furniss, F., Walter, A., 2001. Anxiety in high-functioning children with autism. Autism 5, 277-286. Giros, B., Jaber, M., Jones, S.R., Wightman, R.M., Caron, M.G., 1996. Hyperlocomotion and indifference to cocaine and amphetamine in mice lacking the dopamine transporter. Nature 379, 606-612.

Godar, S.C., Mosher, L.J., Strathman, H.J., Gochi, A.M., Jones, C.M., Fowler, S.C., Bortolato, M., 2015. The D1CT-7 mouse model of Tourette syndrome displays sensorimotor gating deficits in response to spatial confinement. Br J Pharmacol.

Goldman, S., Wang, C., Salgado, M.W., Greene, P.E., Kim, M., Rapin, I., 2009. Motor stereotypies in children with autism and other developmental disorders. Developmental medicine and child neurology 51, 30-38. Gormanns, P., Mueller, N.S., Ditzen, C., Wolf, S., Holsboer, F., Turck, C.W., 2011. Phenome-transcriptome correlation unravels anxiety and depression related pathways. Journal of psychiatric research 45, 973-979. Gottesman, II, Gould, T.D., 2003. The endophenotype concept in psychiatry: etymology and strategic intentions. Am J Psychiatry 160, 636-645.

Gottesman, I.I., McGue, M., in press. Endophenotype, in: Cautin, R., Lilienfeld, S. (Eds.), Encyclopedia of Clinical Psychology. Wiley-Blackwell, Hoboken, NJ, pp. 1-23.

Gould, T.D., Gottesman, II, 2006. Psychiatric endophenotypes and the development of valid animal models. Genes Brain Behav 5, 113-119.

Greco, B., Manago, F., Tucci, V., Kao, H.T., Valtorta, F., Benfenati, F., 2013. Autism-related behavioral abnormalities in synapsin knockout mice. Behavioural brain research 251, 65-74. 
Green, J., Collins, C., Kyzar, E.J., Pham, M., Roth, A., Gaikwad, S., Cachat, J., Stewart, A.M., Landsman, S., Grieco, F., Tegelenbosch, R., Noldus, L.P., Kalueff, A.V., 2012. Automated high-throughput neurophenotyping of zebrafish social behavior. Journal of neuroscience methods 210, 266-271.

Griebel, G., Holmes, A., 2013. 50 years of hurdles and hope in anxiolytic drug discovery. Nature reviews. Drug discovery $12,667-687$.

Guariglia, S.R., Chadman, K.K., 2013. Water T-maze: a useful assay for determination of repetitive behaviors in mice. Journal of neuroscience methods 220, 24-29.

Guilmatre, A., Huguet, G., Delorme, R., Bourgeron, T., 2014. The emerging role of SHANK genes in neuropsychiatric disorders. Developmental neurobiology 74, 113-122.

Hahn, M.E., Karkowski, L., Weinreb, L., Henry, A., Schanz, N., Hahn, E.M., 1998. Genetic and developmental influences on infant mouse ultrasonic calling. II. Developmental patterns in the calls of mice 2-12 days of age. Behavior genetics 28, 315-325.

Hamilton, S.M., Spencer, C.M., Harrison, W.R., Yuva-Paylor, L.A., Graham, D.F., Daza, R.A., Hevner, R.F., Overbeek, P.A., Paylor, R., 2011. Multiple autism-like behaviors in a novel transgenic mouse model.

Behavioural brain research 218, 29-41.

Hansen, R.L., Rogers, S.J., Publishing, A.P., 2013. Autism and Other Neurodevelopmental Disorders. American Psychiatric Pub.

Hara, H., 2007. Autism and epilepsy: a retrospective follow-up study. Brain \& development 29, 486-490.

Hebb, D.O., Williams, K., 1946. A method of rating animal intelligence. J Gen Psychol 34, 59-65.

Hendley, E.D., Ohlsson, W.G., 1991. Two new inbred rat strains derived from SHR: WKHA, hyperactive, and WKHT, hypertensive, rats. The American journal of physiology 261, H583-589.

Hess, E.J., Collins, K.A., Wilson, M.C., 1996. Mouse model of hyperkinesis implicates SNAP-25 in behavioral regulation. J Neurosci 16, 3104-3111.

Holmes, A., Murphy, D.L., Crawley, J.N., 2002. Reduced aggression in mice lacking the serotonin transporter. Psychopharmacology 161, 160-167.

Holmes, A., Yang, R.J., Lesch, K.P., Crawley, J.N., Murphy, D.L., 2003. Mice lacking the serotonin transporter exhibit 5-HT(1A) receptor-mediated abnormalities in tests for anxiety-like behavior.

Neuropsychopharmacology : official publication of the American College of Neuropsychopharmacology 28, 2077-2088.

Homberg, J.R., 2012. The stress-coping (mis)match hypothesis for nature x nurture interactions. Brain research 1432, 114-121.

Homberg, J.R., Kyzar, E.J., Stewart, A.M., Nguyen, M., Poudel, M.K., Echevarria, D.J., Collier, A.D., Gaikwad, S., Klimenko, V.M., Norton, W., Pittman, J., Nakamura, S., Koshiba, M., Yamanouchi, H., Apryatin, S.A., Scattoni, M.L., Diamond, D.M., Ullmann, J.F., Parker, M.O., Brown, R.E., Song, C., Kalueff, A.V., 2015. Improving treatment of neurodevelopmental disorders: Recommendations based on preclinical studies. Expert Opin Drug Discov.

Homberg, J.R., Pattij, T., Janssen, M.C., Ronken, E., De Boer, S.F., Schoffelmeer, A.N., Cuppen, E., 2007a. Serotonin transporter deficiency in rats improves inhibitory control but not behavioural flexibility. The European journal of neuroscience 26, 2066-2073.

Homberg, J.R., Schiepers, O.J., Schoffelmeer, A.N., Cuppen, E., Vanderschuren, L.J., 2007b. Acute and constitutive increases in central serotonin levels reduce social play behaviour in peri-adolescent rats.

Psychopharmacology 195, 175-182.

Homberg, J.R., Schubert, D., Gaspar, P., 2010. New perspectives on the neurodevelopmental effects of SSRIs. Trends in pharmacological sciences 31, 60-65.

Hu, W.F., Chahrour, M.H., Walsh, C.A., 2014. The diverse genetic landscape of neurodevelopmental disorders. Annual review of genomics and human genetics 15, 195-213.

Huang, J., Zhong, Z., Wang, M., Chen, X., Tan, Y., Zhang, S., He, W., He, X., Huang, G., Lu, H., Wu, P., Che, Y., Yan, Y.L., Postlethwait, J.H., Chen, W., Wang, H., 2015. Circadian modulation of dopamine levels and dopaminergic neuron development contributes to attention deficiency and hyperactive behavior. J Neurosci 35, 2572-2587. 
Hunsaker, M.R., 2012. Comprehensive neurocognitive endophenotyping strategies for mouse models of genetic disorders. Progress in neurobiology 96, 220-241.

Ikeda, M., Okahisa, Y., Aleksic, B., Won, M., Kondo, N., Naruse, N., Aoyama-Uehara, K., Sora, I., Iyo, M., Hashimoto, R., Kawamura, Y., Nishida, N., Miyagawa, T., Takeda, M., Sasaki, T., Tokunaga, K., Ozaki, N., Ujike, H., Iwata, N., 2013. Evidence for shared genetic risk between methamphetamine-induced psychosis and schizophrenia. Neuropsychopharmacology : official publication of the American College of Neuropsychopharmacology 38, 1864-1870.

Insel, T., Cuthbert, B., Garvey, M., Heinssen, R., Pine, D.S., Quinn, K., Sanislow, C., Wang, P., 2010. Research domain criteria (RDoC): toward a new classification framework for research on mental disorders. The American journal of psychiatry 167, 748-751.

Insel, T.R., 2014. The NIMH Research Domain Criteria (RDoC) Project: precision medicine for psychiatry. The American journal of psychiatry 171, 395-397.

Iverson, J.M., Braddock, B.A., 2013. Gesture and motor skill in relation to language in children with language impairment. J Speech Lang Hear Res 54, 72-86.

Ivleva, E.I., Morris, D.W., Moates, A.F., Suppes, T., Thaker, G.K., Tamminga, C.A., 2010. Genetics and intermediate phenotypes of the schizophrenia--bipolar disorder boundary. Neuroscience and biobehavioral reviews 34, 897-921.

Jaber, M., Dumartin, B., Sagne, C., Haycock, J.W., Roubert, C., Giros, B., Bloch, B., Caron, M.G., 1999.

Differential regulation of tyrosine hydroxylase in the basal ganglia of mice lacking the dopamine transporter. The European journal of neuroscience 11, 3499-3511.

Jaffee, S.R., Price, T.S., 2007. Gene-environment correlations: a review of the evidence and implications for prevention of mental illness. Mol Psychiatry 12, 432-442.

Jamain, S., Radyushkin, K., Hammerschmidt, K., Granon, S., Boretius, S., Varoqueaux, F., Ramanantsoa, N., Gallego, J., Ronnenberg, A., Winter, D., Frahm, J., Fischer, J., Bourgeron, T., Ehrenreich, H., Brose, N., 2008. Reduced social interaction and ultrasonic communication in a mouse model of monogenic heritable autism. Proceedings of the National Academy of Sciences of the United States of America 105, 1710-1715. Jeste, S.S., 2011. The neurology of autism spectrum disorders. Current opinion in neurology 24, 132-139. Jones, M.D., Williams, M.E., Hess, E.J., 2001. Abnormal presynaptic catecholamine regulation in a hyperactive SNAP-25-deficient mouse mutant. Pharmacology, biochemistry, and behavior 68, 669-676.

Kalueff, A.V., Aldridge, J.W., LaPorte, J.L., Murphy, D.L., Tuohimaa, P., 2007a. Analyzing grooming microstructure in neurobehavioral experiments. Nature protocols 2, 2538-2544.

Kalueff, A.V., Echevarria, D.J., Stewart, A.M., 2014a. Gaining translational momentum: more zebrafish models for neuroscience research. Progress in neuro-psychopharmacology \& biological psychiatry 55, 1-6.

Kalueff, A.V., Fox, M.A., Gallagher, P.S., Murphy, D.L., 2007b. Hypolocomotion, anxiety and serotonin syndrome-like behavior contribute to the complex phenotype of serotonin transporter knockout mice. Genes, brain, and behavior 6, 389-400.

Kalueff, A.V., Gebhardt, M., Stewart, A.M., Cachat, J.M., Brimmer, M., Chawla, J.S., Craddock, C., Kyzar, E.J., Roth, A., Landsman, S., Gaikwad, S., Robinson, K., Baatrup, E., Tierney, K., Shamchuk, A., Norton, W., Miller, N., Nicolson, T., Braubach, O., Gilman, C.P., Pittman, J., Rosemberg, D.B., Gerlai, R., Echevarria, D., Lamb, E., Neuhauss, S.C., Weng, W., Bally-Cuif, L., Schneider, H., Zebrafish Neuroscience Research, C., 2013. Towards a comprehensive catalog of zebrafish behavior 1.0 and beyond. Zebrafish 10, 70-86.

Kalueff, A.V., Keisala, T., Minasyan, A., Kumar, S.R., LaPorte, J.L., Murphy, D.L., Tuohimaa, P., 2008a. The regular and light-dark Suok tests of anxiety and sensorimotor integration: utility for behavioral characterization in laboratory rodents. Nature protocols 3, 129-136.

Kalueff, A.V., Lou, Y.R., Laaksi, I., Tuohimaa, P., 2004. Impaired motor performance in mice lacking neurosteroid vitamin $D$ receptors. Brain research bulletin 64, 25-29.

Kalueff, A.V., Minasyan, A., Keisala, T., Shah, Z.H., Tuohimaa, P., 2006. Hair barbering in mice: implications for neurobehavioural research. Behavioural processes 71, 8-15. 
Kalueff, A.V., Olivier, J.D., Nonkes, L.J., Homberg, J.R., 2010. Conserved role for the serotonin transporter gene in rat and mouse neurobehavioral endophenotypes. Neuroscience and biobehavioral reviews $34,373-$ 386.

Kalueff, A.V., Ren-Patterson, R.F., LaPorte, J.L., Murphy, D.L., 2008b. Domain interplay concept in animal models of neuropsychiatric disorders: a new strategy for high-throughput neurophenotyping research. Behavioural brain research 188, 243-249.

Kalueff, A.V., Ren-Patterson, R.F., Murphy, D.L., 2007c. The developing use of heterozygous mutant mouse models in brain monoamine transporter research. Trends Pharmacol Sci 28, 122-127.

Kalueff, A.V., Stewart, A.M., 2015. Modeling neuropsychiatric spectra to empower translational biological psychiatry. Behavioural brain research 276, 1-7.

Kalueff, A.V., Stewart, A.M., Gerlai, R., 2014b. Zebrafish as an emerging model for studying complex brain disorders. Trends in pharmacological sciences 35, 63-75.

Kalueff, A.V., Stewart, A.M., Gottesman, II, 2014c. Rethinking CNS disorders: time for new drug targets? Trends Pharmacol Sci 35, 491-492.

Kalueff, A.V., Stewart, A.M., Song, C., Gottesman, II, 2015. Targeting dynamic interplay among disordered domains or endophenotypes to understand complex neuropsychiatric disorders: Translational lessons from preclinical models. Neurosci Biobehav Rev 53, 25-36.

Kalueff, A.V., Tuohimaa, P., 2004a. Contrasting grooming phenotypes in C57BI/6 and 129S1/SvImJ mice. Brain research 1028, 75-82.

Kalueff, A.V., Tuohimaa, P., 2004b. Grooming analysis algorithm for neurobehavioural stress research. Brain research. Brain research protocols 13, 151-158.

Kalueff, A.V., Tuohimaa, P., 2005a. Contrasting grooming phenotypes in three mouse strains markedly different in anxiety and activity (129S1, BALB/c and NMRI). Behavioural brain research 160, 1-10.

Kalueff, A.V., Tuohimaa, P., 2005b. The Suok ("ropewalking") murine test of anxiety. Brain Res Brain Res Protoc 14, 87-99.

Kalueff, A.V., Wheaton, M., Murphy, D.L., 2007d. What's wrong with my mouse model? Advances and strategies in animal modeling of anxiety and depression. Behavioural brain research 179, 1-18.

Kalueff, A.V., Wheaton, M., Murphy, D.L., 2007e. What's wrong with my mouse model?: Advances and strategies in animal modeling of anxiety and depression. Behavioural Brain Research 179, 1-18.

Kaneko, T., Mashimo, T., 2015. Creating knockout and knockin rodents using engineered endonucleases via direct embryo injection. Methods Mol Biol 1239, 307-315.

Karino, G.M., T.; Nakamura, S, Kunikata, T., Yamanouchi, H., Koshiba, M., 2015. Timing of changes from a primitive reflex to a voluntary behavior in infancy as a potential predictor of socio-psychological and physical development during juvenile stages among common marmosets. Journal of King Saud University - Science 27, 260-270.

Karvat, G., Kimchi, T., 2012. Systematic autistic-like behavioral phenotyping of 4 mouse strains using a novel wheel-running assay. Behavioural brain research 233, 405-414.

Karvat, G., Kimchi, T., 2014. Acetylcholine elevation relieves cognitive rigidity and social deficiency in a mouse model of autism. Neuropsychopharmacology : official publication of the American College of Neuropsychopharmacology 39, 831-840.

Kaur, K., Simon, A.F., Chauhan, V., Chauhan, A., 2015. Effect of bisphenol A on Drosophila melanogaster behavior--a new model for the studies on neurodevelopmental disorders. Behav Brain Res 284, 77-84.

Kiser, D., Steemers, B., Branchi, I., Homberg, J.R., 2012. The reciprocal interaction between serotonin and social behaviour. Neuroscience and biobehavioral reviews 36, 786-798.

Knutson, B., Burgdorf, J., Panksepp, J., 2002. Ultrasonic vocalizations as indices of affective states in rats. Psychological bulletin 128, 961-977.

Korff, S., Harvey, B.H., 2006. Animal models of obsessive-compulsive disorder: rationale to understanding psychobiology and pharmacology. The Psychiatric clinics of North America 29, 371-390. 
Koshiba, M., Kakei, H., Honda, M., Karino, G., Niitsu, M., Miyaji, T., Kishino, H., Nakamura, S., Kunikata, T., Yamanouchi, H., 2015a. Early-infant diagnostic predictors of the neuro-behavioral development after neonatal care. Behavioural brain research 276, 143-150.

Koshiba, M., Karino, G., Senoo, A., Mimura, K., Shirakawa, Y., Fukushima, Y., Obara, S., Sekihara, H., Ozawa, S., Ikegami, K., Ueda, T., Yamanouchi, H., Nakamura, S., 2013a. Peer attachment formation by systemic redox regulation with social training after a sensitive period. Sci Rep 3, 2503.

Koshiba, M., Mimura, K., Sugiura, Y., Okuya, T., Senoo, A., Ishibashi, H., Nakamura, S., 2011. Reading marmoset behavior 'semantics' under particular social context by multi-parameters correlation analysis. Progress in neuro-psychopharmacology \& biological psychiatry 35, 1499-1504.

Koshiba, M., Senoo, A., Karino, G., Ozawa, S., Tanaka, I., Honda, Y., Usui, S., Kodama, T., Mimura, K., Nakamura, S., Kunikata, T., Yamanouchi, H., Tokuno, H., 2015b. Susceptible period of socio-emotional development affected by constant exposure to daylight. Neuroscience research 93, 91-98.

Koshiba, M., Senoo, A., Mimura, K., Shirakawa, Y., Karino, G., Obara, S., Ozawa, S., Sekihara, H., Fukushima, Y., Ueda, T., Kishino, H., Tanaka, T., Ishibashi, H., Yamanouchi, H., Yui, K., Nakamura, S., 2013b. A cross-species socio-emotional behaviour development revealed by a multivariate analysis. Scientific Reports 3.

Koshiba, M., Shirakawa, Y., Mimura, K., Senoo, A., Karino, G., Nakamura, S., 2013c. Familiarity perception call elicited under restricted sensory cues in peer-social interactions of the domestic chick. PloS one 8, e58847. Koshiba, M.N., S., Mimura, K.; Senoo, A.; Karino, G., Amemiya, S.; Miyaji, T.; Kunikata, T.; Yamanouchi, H., 2013. Socio-emotional development evaluated by Behaviour Output analysis for Quantitative Emotional State Translation: towards early diagnosis of individuals with developmental disorders. OA Autism 1, 18.

Kriegebaum, C., Gutknecht, L., Schmitt, A., Lesch, K.P., Reif, A., 2010. [Serotonin now: Part 1. Neurobiology and developmental genetics]. Fortschritte der Neurologie-Psychiatrie 78, 319-331.

Krishnan, K.R., 2005. Psychiatric and medical comorbidities of bipolar disorder. Psychosom Med 67, 1-8.

Kullyev, A., Dempsey, C.M., Miller, S., Kuan, C.J., Hapiak, V.M., Komuniecki, R.W., Griffin, C.T., Sze, J.Y., 2010. A genetic survey of fluoxetine action on synaptic transmission in Caenorhabditis elegans. Genetics 186, 929941.

Lahvis, G., Black, L., 2011. Social Interactions in the Clinic and the Cage: Toward a More Valid Mouse Model of Autism, in: Raber, J. (Ed.), Animal Models of Behavioral Analysis

Neuromethods pp. 153-192.

Lange, M., Norton, W., Coolen, M., Chaminade, M., Merker, S., Proft, F., Schmitt, A., Vernier, P., Lesch, K.P., Bally-Cuif, L., 2012a. The ADHD-linked gene Lphn3.1 controls locomotor activity and impulsivity in zebrafish. Molecular psychiatry 17, 855.

Lange, M., Norton, W., Coolen, M., Chaminade, M., Merker, S., Proft, F., Schmitt, A., Vernier, P., Lesch, K.P., Bally-Cuif, L., 2012b. The ADHD-susceptibility gene Iphn3.1 modulates dopaminergic neuron formation and locomotor activity during zebrafish development. Molecular psychiatry.

Lange, M., Norton, W., Coolen, M., Chaminade, M., Merker, S., Proft, F., Schmitt, A., Vernier, P., Lesch, K.P., Bally-Cuif, L., 2012c. The ADHD-susceptibility gene Iphn3.1 modulates dopaminergic neuron formation and locomotor activity during zebrafish development. Molecular psychiatry 17, 946-954.

LaPorte, J.L., Egan, R.J., Hart, P.C., Bergner, C.L., Cachat, J.M., Canavello, P.R., Kalueff, A.V., 2010. Qui non proficit, deficit: experimental models for 'integrative' research of affective disorders. Journal of affective disorders 121, 1-9.

Le Strat, Y., Ramoz, N., Gorwood, P., 2009. The role of genes involved in neuroplasticity and neurogenesis in the observation of a gene-environment interaction (GxE) in schizophrenia. Curr Mol Med 9, 506-518.

LeBarton, E.S., Iverson, J.M., 2013. Fine motor skill predicts expressive language in infant siblings of children with autism. Dev Sci 16, 815-827.

Lee, P.C., Dodart, J.C., Aron, L., Finley, L.W., Bronson, R.T., Haigis, M.C., Yankner, B.A., Harper, J.W., 2013. Altered social behavior and neuronal development in mice lacking the Uba6-Use1 ubiquitin transfer system. Mol Cell 50, 172-184. 
Lenzenweger, M.F., 2013. Thinking clearly about the endophenotype-intermediate phenotype-biomarker distinctions in developmental psychopathology research. Development and psychopathology 25, 1347-1357. Leonard, H.C., Bedford, R., Charman, T., Elsabbagh, M., Johnson, M.H., Hill, E.L., 2013. Motor development in children at risk of autism: a follow-up study of infant siblings. Autism 18, 281-291.

Lesch, K.P., Waider, J., 2012. Serotonin in the modulation of neural plasticity and networks: implications for neurodevelopmental disorders. Neuron 76, 175-191.

Lewis, M.H., Tanimura, Y., Lee, L.W., Bodfish, J.W., 2007. Animal models of restricted repetitive behavior in autism. Behavioural brain research 176, 66-74.

Lonetti, G., Angelucci, A., Morando, L., Boggio, E.M., Giustetto, M., Pizzorusso, T., 2010. Early environmental enrichment moderates the behavioral and synaptic phenotype of MeCP2 null mice. Biol Psychiatry 67, 657665.

Lopez-Patino, M.A., Yu, L., Cabral, H., Zhdanova, I.V., 2008. Anxiogenic effects of cocaine withdrawal in zebrafish. Physiology \& behavior 93, 160-171.

Luthman, J., Fredriksson, A., Sundstrom, E., Jonsson, G., Archer, T., 1989. Selective lesion of central dopamine or noradrenaline neuron systems in the neonatal rat: motor behavior and monoamine alterations at adult stage. Behavioural brain research 33, 267-277.

Maccarrone, G., Ditzen, C., Yassouridis, A., Rewerts, C., Uhr, M., Uhlen, M., Holsboer, F., Turck, C.W., 2013. Psychiatric patient stratification using biosignatures based on cerebrospinal fluid protein expression clusters. Journal of psychiatric research 47, 1572-1580.

Macri, S., Onori, M.P., Roessner, V., Laviola, G., 2013a. Animal models recapitulating the multifactorial origin of Tourette syndrome. Int Rev Neurobiol 112, 211-237.

Macri, S., Proietti Onori, M., Laviola, G., 2013b. Theoretical and practical considerations behind the use of laboratory animals for the study of Tourette syndrome. Neurosci Biobehav Rev 37, 1085-1100.

Martinez-Cue, C., Rueda, N., Garcia, E., Florez, J., 2006. Anxiety and panic responses to a predator in male and female Ts65Dn mice, a model for Down syndrome. Genes Brain Behav 5, 413-422.

Martino, D., Laviola, G., 2013. The multifaceted nature of Tourette syndrome: pre-clinical, clinical and therapeutic issues. Neurosci Biobehav Rev 37, 993-996.

McAlonan, K., Brown, V.J., 2003. Orbital prefrontal cortex mediates reversal learning and not attentional set shifting in the rat. Behav Brain Res 146, 97-103.

McFarlane, H.G., Kusek, G.K., Yang, M., Phoenix, J.L., Bolivar, V.J., Crawley, J.N., 2008. Autism-like behavioral phenotypes in BTBR T+tf/J mice. Genes, brain, and behavior 7, 152-163.

McNamara, M.C., Benignus, G., Benignus, V.A., Miller, A.T., Jr., 1977. Active and passive avoidance in rats as a function of age. Exp Aging Res 3, 3-16.

Miceli, S., Negwer, M., van Eijs, F., Kalkhoven, C., van Lierop, I., Homberg, J., Schubert, D., 2013. High

serotonin levels during brain development alter the structural input-output connectivity of neural networks in the rat somatosensory layer IV. Frontiers in cellular neuroscience 7, 88.

Michetti, C.R., L; Scattoni, ML, 2012. Modeling Social Communication Deficits in Mouse Models of Autism. Autism S1:007.

Miller, N., Greene, K., Dydinski, A., Gerlai, R., 2013. Effects of nicotine and alcohol on zebrafish (Danio rerio) shoaling. Behavioural brain research 240, 192-196.

Mimura, K., Kishino, H., Karino, G., Nitta, E., Senoo, A., Ikegami, K., Kunikata, T., Yamanouchi, H., Nakamura, S., Sato, K., Koshiba, M., 2015. Potential of a smartphone as a stress-free sensor of daily human behaviour. Behavioural brain research 276, 181-189.

Mimura, K., Nakamura, S., Koshiba, M., 2013. A flexion period for attachment formation in isolated chicks to unfamiliar peers visualized in a developmental trajectory space through behavioral multivariate correlation analysis. Neuroscience letters 547, 70-75.

Mimura, K.M., M.; Nakamura, S.; Koshiba, M.. 2013. A Sensitive Period of Peer-Social Learning. Journal of Clinical Toxicology 3, 000158. 
Moles, A., Costantini, F., Garbugino, L., Zanettini, C., D'Amato, F.R., 2007. Ultrasonic vocalizations emitted during dyadic interactions in female mice: a possible index of sociability? Behavioural brain research 182, 223-230.

Mook, D.M., Jeffrey, J., Neuringer, A., 1993. Spontaneously hypertensive rats (SHR) readily learn to vary but not repeat instrumental responses. Behavioral and neural biology 59, 126-135.

Morand-Beaulieu, S., O'Connor, K.P., Sauve, G., Blanchet, P.J., Lavoie, M.E., 2015. Cognitive-behavioral therapy induces sensorimotor and specific electrocortical changes in chronic tic and Tourette's disorder. Neuropsychologia.

Morris, R., 1984. Developments of a water-maze procedure for studying spatial learning in the rat. J Neurosci Methods 11, 47-60.

Morrison, R.S., Wenzel, H.J., Kinoshita, Y., Robbins, C.A., Donehower, L.A., Schwartzkroin, P.A., 1996. Loss of the p53 tumor suppressor gene protects neurons from kainate-induced cell death. J Neurosci 16, 1337-1345. Moser, V.C., McCormick, J.P., Creason, J.P., MacPhail, R.C., 1988. Comparison of chlordimeform and carbaryl using a functional observational battery. Fundam Appl Toxicol 11, 189-206.

Moy, S.S., Nadler, J.J., Perez, A., Barbaro, R.P., Johns, J.M., Magnuson, T.R., Piven, J., Crawley, J.N., 2004.

Sociability and preference for social novelty in five inbred strains: an approach to assess autistic-like behavior in mice. Genes, brain, and behavior 3, 287-302.

Moy, S.S., Nadler, J.J., Poe, M.D., Nonneman, R.J., Young, N.B., Koller, B.H., Crawley, J.N., Duncan, G.E., Bodfish, J.W., 2008. Development of a mouse test for repetitive, restricted behaviors: relevance to autism. Behavioural brain research 188, 178-194.

Moy, S.S., Nadler, J.J., Young, N.B., Perez, A., Holloway, L.P., Barbaro, R.P., Barbaro, J.R., Wilson, L.M., Threadgill, D.W., Lauder, J.M., Magnuson, T.R., Crawley, J.N., 2007. Mouse behavioral tasks relevant to autism: phenotypes of 10 inbred strains. Behavioural brain research 176, 4-20.

Murphy, D.L., Lesch, K.P., 2008. Targeting the murine serotonin transporter: insights into human neurobiology. Nature reviews. Neuroscience 9, 85-96.

Myers, M.M., Musty, R.E., Hendley, E.D., 1982. Attenuation of hyperactivity in the spontaneously hypertensive rat by amphetamine. Behavioral and neural biology 34, 42-54.

Nadler, J.J., Moy, S.S., Dold, G., Trang, D., Simmons, N., Perez, A., Young, N.B., Barbaro, R.P., Piven, J., Magnuson, T.R., Crawley, J.N., 2004. Automated apparatus for quantitation of social approach behaviors in mice. Genes, brain, and behavior 3, 303-314.

Nagy, Z.M., Pagano, M., Gable, D., 1976. Differential development of 24-h retention capacities for two components of T-maze escape learning by infant mice. Animal Learning \& Behavior 4, 25-29.

Nithianantharajah, J., Hannan, A.J., 2006. Enriched environments, experience-dependent plasticity and disorders of the nervous system. Nat Rev Neurosci 7, 697-709.

Nordstrom, E.J., Bittner, K.C., McGrath, M.J., Parks, C.R., 3rd, Burton, F.H., 2015. "Hyperglutamatergic corticostriato-thalamo-cortical circuit" breaker drugs alleviate tics in a transgenic circuit model of Tourettes syndrome. Brain Res.

Norton, W., 2011. Measuring larval zebrafish behavior: Locomotion, thigmotaxis and startle. Zebrafish Neurobehavioural Protocols 2.

Nyby, J., 1983. Ultrasonic vocalizations during sex behavior of male house mice (Mus musculus): a description. Behavioral and neural biology 39, 128-134.

Nyby, J.G., 2001. Auditory communication among adults, in: Willott, J.F. (Ed.), Handbook of mouse auditory research: from behavior to molecular biology. CRC, New York, pp. 3-18.

Okamoto, K., Aoki, K., 1963. Development of a strain of spontaneously hypertensive rats. Japanese circulation journal 27, 282-293.

Panksepp, J., 2003. Can anthropomorphic analyses of separation cries in other animals inform us about the emotional nature of social loss in humans? Comment on Blumberg and Sokoloff (2001). Psychological review 110, 376-388; discussion 389-396. 
Parker, C.C., Chen, H., Flagel, S.B., Geurts, A.M., Richards, J.B., Robinson, T.E., Solberg Woods, L.C., Palmer, A.A., 2014a. Rats are the smart choice: Rationale for a renewed focus on rats in behavioral genetics. Neuropharmacology 76 Pt B, 250-258.

Parker, M.O., Annan, L.V., Kanellopoulos, A.H., Brock, A.J., Combe, F.J., Baiamonte, M., Teh, M.T., Brennan, C.H., 2014b. The utility of zebrafish to study the mechanisms by which ethanol affects social behavior and anxiety during early brain development. Progress in neuro-psychopharmacology \& biological psychiatry. Parker, M.O., Brock, A.J., Sudwarts, A., Brennan, C.H., 2014c. Atomoxetine reduces anticipatory responding in a 5-choice serial reaction time task for adult zebrafish. Psychopharmacology 231, 2671-2679.

Parker, M.O., Millington, M.E., Combe, F.J., Brennan, C.H., 2012. Development and implementation of a three-choice serial reaction time task for zebrafish (Danio rerio). Behavioural brain research 227, 73-80. Pearson, B.L., Bettis, J.K., Meyza, K.Z., Yamamoto, L.Y., Blanchard, D.C., Blanchard, R.J., 2012. Absence of social conditioned place preference in BTBR T+tf/J mice: relevance for social motivation testing in rodent models of autism. Behavioural brain research 233, 99-104.

Pearson, B.L., Pobbe, R.L., Defensor, E.B., Oasay, L., Bolivar, V.J., Blanchard, D.C., Blanchard, R.J., 2011. Motor and cognitive stereotypies in the BTBR T+tf/J mouse model of autism. Genes, brain, and behavior 10, 228235.

Peca J, Feliciano C, Ting JT, Wang W, Wells MF, Venkatraman TN, al., e., 2011. Shank3 mutant mice display autistic-like behaviours and striatal dysfunction. Nature 472, 437-442.

Peca, J., Feliciano, C., Ting, J.T., Wang, W., Wells, M.F., Venkatraman, T.N., Lascola, C.D., Fu, Z., Feng, G., 2011. Shank3 mutant mice display autistic-like behaviours and striatal dysfunction. Nature 472, 437-442.

Penagarikano, O., Abrahams, B.S., Herman, E.I., Winden, K.D., Gdalyahu, A., Dong, H., Sonnenblick, L.I., Gruver, R., Almajano, J., Bragin, A., Golshani, P., Trachtenberg, J.T., Peles, E., Geschwind, D.H., 2011. Absence of CNTNAP2 leads to epilepsy, neuronal migration abnormalities, and core autism-related deficits. Cell 147, 235-246.

Perry, W., Minassian, A., Henry, B., Kincaid, M., Young, J.W., Geyer, M.A., 2010. Quantifying over-activity in bipolar and schizophrenia patients in a human open field paradigm. Psychiatry Res 178, 84-91.

Perry, W., Minassian, A., Paulus, M.P., Young, J.W., Kincaid, M.J., Ferguson, E.J., Henry, B.L., Zhuang, X., Masten, V.L., Sharp, R.F., Geyer, M.A., 2009. A reverse-translational study of dysfunctional exploration in psychiatric disorders: from mice to men. Arch Gen Psychiatry 66, 1072-1080.

Persico, A.M., Mengual, E., Moessner, R., Hall, F.S., Revay, R.S., Sora, I., Arellano, J., DeFelipe, J., GimenezAmaya, J.M., Conciatori, M., Marino, R., Baldi, A., Cabib, S., Pascucci, T., Uhl, G.R., Murphy, D.L., Lesch, K.P., Keller, F., 2001. Barrel pattern formation requires serotonin uptake by thalamocortical afferents, and not vesicular monoamine release. The Journal of neuroscience : the official journal of the Society for Neuroscience 21, 6862-6873.

Phagava, H., Muratori, F., Einspieler, C., Maestro, S., Apicella, F., Guzzetta, A., Prechtl, H.F., Cioni, G., 2008. General movements in infants with autism spectrum disorders. Georgian medical news, 100-105.

Pinto, L.H., Enroth-Cugell, C., 2000. Tests of the mouse visual system. Mamm Genome 11, 531-536. Pogorelov, V.M., Rodriguiz, R.M., Insco, M.L., Caron, M.G., Wetsel, W.C., 2005. Novelty seeking and stereotypic activation of behavior in mice with disruption of the Dat1 gene. Neuropsychopharmacology 30 , 1818-1831.

Porrino, L.J., Rapoport, J.L., Behar, D., Sceery, W., Ismond, D.R., Bunney, W.E., Jr., 1983. A naturalistic assessment of the motor activity of hyperactive boys. I. Comparison with normal controls. Archives of general psychiatry 40, 681-687.

Pritchett, K., Mulder, G., 2004. Hebb-Williams mazes. Contemp Top Lab Anim Sci 43, 44-45.

Raber, J., Mehta, P.P., Kreifeldt, M., Parsons, L.H., Weiss, F., Bloom, F.E., Wilson, M.C., 1997. Coloboma hyperactive mutant mice exhibit regional and transmitter-specific deficits in neurotransmission. Journal of neurochemistry 68, 176-186.

Radyushkin, K., Hammerschmidt, K., Boretius, S., Varoqueaux, F., El-Kordi, A., Ronnenberg, A., Winter, D., Frahm, J., Fischer, J., Brose, N., Ehrenreich, H., 2009. Neuroligin-3-deficient mice: model of a monogenic heritable form of autism with an olfactory deficit. Genes, brain, and behavior 8, 416-425. 
Rapanelli, M., Pittenger, C., 2015. Histamine and histamine receptors in Tourette syndrome and other neuropsychiatric conditions. Neuropharmacology.

Rebello, T.J., Yu, Q., Goodfellow, N.M., Caffrey Cagliostro, M.K., Teissier, A., Morelli, E., Demireva, E.Y., Chemiakine, A., Rosoklija, G.B., Dwork, A.J., Lambe, E.K., Gingrich, J.A., Ansorge, M.S., 2014. Postnatal day 2 to 11 constitutes a 5-HT-sensitive period impacting adult mPFC function. The Journal of neuroscience : the official journal of the Society for Neuroscience 34, 12379-12393.

Redei, E.E., Ahmadiyeh, N., Baum, A.E., Sasso, D.A., Slone, J.L., Solberg, L.C., Will, C.C., Volenec, A., 2001. Novel animal models of affective disorders. Seminars in clinical neuropsychiatry 6, 43-67.

Reiter, L., 1978. An introduction to neurobehavioral toxicology. Environ Health Perspect 26, 5-7.

Restivo, L., Ferrari, F., Passino, E., Sgobio, C., Bock, J., Oostra, B.A., Bagni, C., Ammassari-Teule, M., 2005. Enriched environment promotes behavioral and morphological recovery in a mouse model for the fragile $X$ syndrome. Proc Natl Acad Sci U S A 102, 11557-11562.

Reynolds, S., Urruela, M., Devine, D.P., 2013. Effects of environmental enrichment on repetitive behaviors in the BTBR T+tf/J mouse model of autism. Autism research : official journal of the International Society for Autism Research 6, 337-343.

Ricceri, L., Moles, A., Crawley, J., 2007. Behavioral phenotyping of mouse models of neurodevelopmental disorders: relevant social behavior patterns across the life span. Behav Brain Res 176, 40-52.

Rice, D., Barone, S., 2000. Critical periods of vulnerability for the developing nervous system: evidence from humans and animal models. Environmental Health Perspectives 108, 511-533.

Romano, E., Michetti, C., Caruso, A., Laviola, G., Scattoni, M.L., 2013. Characterization of neonatal vocal and motor repertoire of reelin mutant mice. PloS one 8, e64407.

Roubertoux, P.L., Baumann, L., Ragueneau, S., Semal, C., 1987. Early development in mice. IV. Age at disappearance of the rooting response: genetic analysis in newborn mice. Behav Genet 17, 453-464.

Roubertoux, P.L., Martin, B., Le Roy, I., Beau, J., Marchaland, C., Perez-Diaz, F., Cohen-Salmon, C., Carlier, M., 1996. Vocalizations in newborn mice: genetic analysis. Behavior genetics 26, 427-437.

Roullet, F.I., Crawley, J.N., 2011. Mouse models of autism: testing hypotheses about molecular mechanisms. Current topics in behavioral neurosciences 7, 187-212.

Roy, S., Watkins, N., Heck, D., 2012. Comprehensive analysis of ultrasonic vocalizations in a mouse model of fragile $x$ syndrome reveals limited, call type specific deficits. PloS one 7, e44816.

Russell, V.A., 2002. Hypodopaminergic and hypernoradrenergic activity in prefrontal cortex slices of an animal model for attention-deficit hyperactivity disorder--the spontaneously hypertensive rat. Behavioural brain research 130, 191-196.

Sadler, T.W., 2006. Langman's Medical Embryology. Lippincott Williams \& Wilkins.

Sagvolden, T., 2000. Behavioral validation of the spontaneously hypertensive rat (SHR) as an animal model of attention-deficit/hyperactivity disorder (AD/HD). Neuroscience and biobehavioral reviews 24, 31-39.

Sagvolden, T., 2006. The alpha-2A adrenoceptor agonist guanfacine improves sustained attention and reduces overactivity and impulsiveness in an animal model of Attention-Deficit/Hyperactivity Disorder (ADHD). Behav Brain Funct 2, 41.

Sagvolden, T., Metzger, M.A., Schiorbeck, H.K., Rugland, A.L., Spinnangr, I., Sagvolden, G., 1992. The spontaneously hypertensive rat (SHR) as an animal model of childhood hyperactivity (ADHD): changed reactivity to reinforcers and to psychomotor stimulants. Behavioral and neural biology 58, 103-112.

Saili, K.S., Corvi, M.M., Weber, D.N., Patel, A.U., Das, S.R., Przybyla, J., Anderson, K.A., Tanguay, R.L., 2012. Neurodevelopmental low-dose bisphenol A exposure leads to early life-stage hyperactivity and learning deficits in adult zebrafish. Toxicology 291, 83-92.

Sala, M., Braida, D., Donzelli, A., Martucci, R., Busnelli, M., Bulgheroni, E., Rubino, T., Parolaro, D., Nishimori, K., Chini, B., 2013. Mice heterozygous for the oxytocin receptor gene $(O x \operatorname{tr}(+/-))$ show impaired social behaviour but not increased aggression or cognitive inflexibility: evidence of a selective haploinsufficiency gene effect. Journal of neuroendocrinology 25, 107-118.

Sala, M., Braida, D., Lentini, D., Busnelli, M., Bulgheroni, E., Capurro, V., Finardi, A., Donzelli, A., Pattini, L., Rubino, T., Parolaro, D., Nishimori, K., Parenti, M., Chini, B., 2011. Pharmacologic rescue of impaired cognitive 
flexibility, social deficits, increased aggression, and seizure susceptibility in oxytocin receptor null mice: a neurobehavioral model of autism. Biol Psychiatry 69, 875-882.

Sales, G.D., 1972. Ultrasound and aggressive behaviour in rats and other small mammals. Animal behaviour 20, 88-100.

Sansa, G., Carlson, C., Doyle, W., Weiner, H.L., Bluvstein, J., Barr, W., Devinsky, O., 2011. Medically refractory epilepsy in autism. Epilepsia 52, 1071-1075.

Scattoni, M.L., Crawley, J., Ricceri, L., 2009. Ultrasonic vocalizations: a tool for behavioural phenotyping of mouse models of neurodevelopmental disorders. Neuroscience and biobehavioral reviews 33, 508-515.

Scattoni, M.L., Gandhy, S.U., Ricceri, L., Crawley, J.N., 2008. Unusual repertoire of vocalizations in the BTBR $\mathrm{T}+\mathrm{tf} / \mathrm{J}$ mouse model of autism. PloS one 3, e3067.

Scattoni, M.L., Ricceri, L., Crawley, J.N., 2011. Unusual repertoire of vocalizations in adult BTBR T+tf/J mice during three types of social encounters. Genes, brain, and behavior 10, 44-56.

Scheggia, D., Bebensee, A., Weinberger, D.R., Papaleo, F., 2014. The ultimate intra-/extra-dimensional attentional set-shifting task for mice. Biol Psychiatry 75, 660-670.

Schmeisser, M.J., 2015. Translational neurobiology in Shank mutant mice - Model systems for neuropsychiatric disorders. Annals of anatomy = Anatomischer Anzeiger : official organ of the Anatomische Gesellschaft 200, 115-117.

Schmeisser, M.J., Ey, E., Wegener, S., Bockmann, J., Stempel, A.V., Kuebler, A., Janssen, A.L., Udvardi, P.T., Shiban, E., Spilker, C., Balschun, D., Skryabin, B.V., Dieck, S., Smalla, K.H., Montag, D., Leblond, C.S., Faure, P., Torquet, N., Le Sourd, A.M., Toro, R., Grabrucker, A.M., Shoichet, S.A., Schmitz, D., Kreutz, M.R., Bourgeron, T., Gundelfinger, E.D., Boeckers, T.M., 2012. Autistic-like behaviours and hyperactivity in mice lacking ProSAP1/Shank2. Nature 486, 256-260.

Seibt, K.J., Oliveira Rda, L., Zimmermann, F.F., Capiotti, K.M., Bogo, M.R., Ghisleni, G., Bonan, C.D., 2010. Antipsychotic drugs prevent the motor hyperactivity induced by psychotomimetic MK-801 in zebrafish (Danio rerio). Behavioural brain research 214, 417-422.

Senoo, A., Okuya, T., Sugiura, Y., Mimura, K., Honda, Y., Tanaka, I., Kodama, T., Tokuno, H., Yui, K., Nakamura, S., Usui, S., Koshiba, M., 2011. Effects of constant daylight exposure during early development on marmoset psychosocial behavior. Progress in neuro-psychopharmacology \& biological psychiatry 35, 1493-1498.

Sewell, G.D., 1970. Ultrasonic communication in rodents. Nature 227, 410.

Shair, H.N., Brunelli, S.A., Masmela, J.R., Boone, E., Hofer, M.A., 2003. Social, thermal, and temporal influences on isolation-induced and maternally potentiated ultrasonic vocalizations of rat pups.

Developmental psychobiology 42, 206-222.

Shirakawa, Y.M., K.; Senoo, A.; Fujii, K.; Shimizu, T., Saga, T.; Tanaka, I.; Honda, Y.; Tokuno, Hironobu.; Usui, S.; Kodama, T.; Tsugawa, W.; Sode, K.; Nakamura, S.; Koshiba, M., 2013a. Multivariate correlation analysis suggested high ubiquinol and low ubiquinone in plasma promoted primates' social motivation and IR detected lower body temperature. Journal of Clinical Toxicology 3, 1000160.

Shirakawa, Y.N., S., Koshiba, M., 2013b. Peer-Social Network Development Revealed by the Brain Multivariate Correlation Map with 10 Monoamines and 11 Behaviors. Journal of Clinical Toxicology 3, 1000161.

Silverman, J.L., Crawley, J.N., 2014. The promising trajectory of autism therapeutics discovery. Drug discovery today $19,838-844$.

Silverman, J.L., Smith, D.G., Rizzo, S.J., Karras, M.N., Turner, S.M., Tolu, S.S., Bryce, D.K., Smith, D.L., Fonseca, K., Ring, R.H., Crawley, J.N., 2012. Negative allosteric modulation of the mGluR5 receptor reduces repetitive behaviors and rescues social deficits in mouse models of autism. Science translational medicine 4, 131 ra151. Silverman, J.L., Tolu, S.S., Barkan, C.L., Crawley, J.N., 2010a. Repetitive self-grooming behavior in the BTBR mouse model of autism is blocked by the mGluR5 antagonist MPEP. Neuropsychopharmacology 35, 976-989. Silverman, J.L., Yang, M., Lord, C., Crawley, J.N., 2010b. Behavioural phenotyping assays for mouse models of autism. Nat Rev Neurosci 11, 490-502.

Simpson, K.L., Weaver, K.J., de Villers-Sidani, E., Lu, J.Y., Cai, Z., Pang, Y., Rodriguez-Porcel, F., Paul, I.A., Merzenich, M., Lin, R.C., 2011. Perinatal antidepressant exposure alters cortical network function in rodents. Proceedings of the National Academy of Sciences of the United States of America 108, 18465-18470. 
Smit-Rigter, L.A., Noorlander, C.W., von Oerthel, L., Chameau, P., Smidt, M.P., van Hooft, J.A., 2012. Prenatal fluoxetine exposure induces life-long serotonin 5-HT(3) receptor-dependent cortical abnormalities and anxiety-like behaviour. Neuropharmacology 62, 865-870.

Sontag, T.A., Tucha, O., Walitza, S., Lange, K.W., 2010. Animal models of attention deficit/hyperactivity disorder (ADHD): a critical review. Attention deficit and hyperactivity disorders 2, 1-20.

Sora, I., Wichems, C., Takahashi, N., Li, X.F., Zeng, Z., Revay, R., Lesch, K.P., Murphy, D.L., Uhl, G.R., 1998. Cocaine reward models: conditioned place preference can be established in dopamine- and in serotonintransporter knockout mice. Proceedings of the National Academy of Sciences of the United States of America 95, 7699-7704.

Spencer, C.M., Alekseyenko, O., Serysheva, E., Yuva-Paylor, L.A., Paylor, R., 2005. Altered anxiety-related and social behaviors in the Fmr1 knockout mouse model of fragile X syndrome. Genes, brain, and behavior 4, 420430.

Stewart, A.M., Braubach, O., Spitsbergen, J., Gerlai, R., Kalueff, A.V., 2014a. Zebrafish models for translational neuroscience research: from tank to bedside. Trends in neurosciences 37, 264-278.

Stewart, A.M., Gerlai, R., Kalueff, A.V., 2015a. Developing highER-throughput zebrafish screens for in-vivo CNS drug discovery. Front Behav Neurosci 9, 14.

Stewart, A.M., Grieco, F., Tegelenbosch, R.A., Kyzar, E.J., Nguyen, M., Kaluyeva, A., Song, C., Noldus, L.P., Kalueff, A.V., 2015b. A novel 3D method of locomotor analysis in adult zebrafish: Implications for automated detection of CNS drug-evoked phenotypes. J Neurosci Methods.

Stewart, A.M., Kalueff, A.V., 2015. Developing better and more valid animal models of brain disorders. Behavioural brain research 276, 28-31.

Stewart, A.M., Nguyen, M., Song, C., Kalueff, A.V., 2015c. Understanding the genetic architectonics of complex CNS traits: Lost by the association, but found in the interaction? J Psychopharmacol 29, 872-877. Stewart, A.M., Nguyen, M., Wong, K., Poudel, M.K., Kalueff, A.V., 2014b. Developing zebrafish models of autism spectrum disorder (ASD). Progress in neuro-psychopharmacology \& biological psychiatry 50, 27-36. Stewart, A.M., Ullmann, J.F., Norton, W.H., Parker, M.O., Brennan, C.H., Gerlai, R., Kalueff, A.V., 2015 d. Molecular psychiatry of zebrafish. Mol Psychiatry 20, 2-17.

Sullivan, R.M., Wilson, D.A., 1995. Dissociation of behavioral and neural correlates of early associative learning. Dev Psychobiol 28, 213-219.

Sungur, A.O., Vorckel, K.J., Schwarting, R.K., Wohr, M., 2014. Repetitive behaviors in the Shank1 knockout mouse model for autism spectrum disorder: developmental aspects and effects of social context. Journal of neuroscience methods 234, 92-100.

Tait, D.S., Chase, E.A., Brown, V.J., 2014. Attentional set-shifting in rodents: a review of behavioural methods and pharmacological results. Curr Pharm Des 20, 5046-5059.

Thomas, A., Burant, A., Bui, N., Graham, D., Yuva-Paylor, L.A., Paylor, R., 2009. Marble burying reflects a repetitive and perseverative behavior more than novelty-induced anxiety. Psychopharmacology 204, 361-

373.

Turner, C.A., Presti, M.F., Newman, H.A., Bugenhagen, P., Crnic, L., Lewis, M.H., 2001. Spontaneous stereotypy in an animal model of Down syndrome: Ts65Dn mice. Behavior genetics 31, 393-400.

Tyzio, R., Nardou, R., Ferrari, D.C., Tsintsadze, T., Shahrokhi, A., Eftekhari, S., Khalilov, I., Tsintsadze, V., Brouchoud, C., Chazal, G., Lemonnier, E., Lozovaya, N., Burnashev, N., Ben-Ari, Y., 2014. Oxytocin-mediated GABA inhibition during delivery attenuates autism pathogenesis in rodent offspring. Science (New York, N.Y 343, 675-679.

Ullmann, J.F., Calamante, F., Collin, S.P., Reutens, D.C., Kurniawan, N.D., 2015. Enhanced characterization of the zebrafish brain as revealed by super-resolution track-density imaging. Brain Struct Funct 220, 457-468. Ullmann, J.F., Cowin, G., Kurniawan, N.D., Collin, S.P., 2010. A three-dimensional digital atlas of the zebrafish brain. Neuroimage 51, 76-82.

van den Bergh, F.S., Bloemarts, E., Chan, J.S., Groenink, L., Olivier, B., Oosting, R.S., 2006. Spontaneously hypertensive rats do not predict symptoms of attention-deficit hyperactivity disorder. Pharmacology, biochemistry, and behavior 83, 380-390. 
van der Voet, M., Harich, B., Franke, B., Schenck, A., 2015. ADHD-associated dopamine transporter, latrophilin and neurofibromin share a dopamine-related locomotor signature in Drosophila. Mol Psychiatry. Van Raamsdonk, J.M., Pearson, J., Slow, E.J., Hossain, S.M., Leavitt, B.R., Hayden, M.R., 2005. Cognitive dysfunction precedes neuropathology and motor abnormalities in the YAC128 mouse model of Huntington's disease. J Neurosci 25, 4169-4180.

Van Schalkwyk, G.I., Lewis, A.S., Qayyum, Z., Koslosky, K., Picciotto, M.R., Volkmar, F.R., 2015. Reduction of Aggressive Episodes After Repeated Transdermal Nicotine Administration in a Hospitalized Adolescent with Autism Spectrum Disorder. Journal of autism and developmental disorders.

van Steensel, F.J., Bogels, S.M., Perrin, S., 2011. Anxiety disorders in children and adolescents with autistic spectrum disorders: a meta-analysis. Clinical child and family psychology review 14, 302-317.

Vandenbergh, D.J., Persico, A.M., Hawkins, A.L., Griffin, C.A., Li, X., Jabs, E.W., Uhl, G.R., 1992. Human dopamine transporter gene (DAT1) maps to chromosome 5 p15.3 and displays a VNTR. Genomics 14, 11041106.

Veenstra-VanderWeele, J., Muller, C.L., Iwamoto, H., Sauer, J.E., Owens, W.A., Shah, C.R., Cohen, J., Mannangatti, P., Jessen, T., Thompson, B.J., Ye, R., Kerr, T.M., Carneiro, A.M., Crawley, J.N., Sanders-Bush, E., McMahon, D.G., Ramamoorthy, S., Daws, L.C., Sutcliffe, J.S., Blakely, R.D., 2012. Autism gene variant causes hyperserotonemia, serotonin receptor hypersensitivity, social impairment and repetitive behavior. Proceedings of the National Academy of Sciences of the United States of America 109, 5469-5474. Viggiano, D., Grammatikopoulos, G., Sadile, A.G., 2002. A morphometric evidence for a hyperfunctioning mesolimbic system in an animal model of ADHD. Behavioural brain research 130, 181-189.

Vorhees, C.V., Butcher, R.E., Brunner, R.L., Sobotka, T.J., 1979. A developmental test battery for neurobehavioral toxicity in rats: a preliminary analysis using monosodium glutamate calcium carrageenan, and hydroxyurea. Toxicol Appl Pharmacol 50, 267-282.

Wang, X., McCoy, P.A., Rodriguiz, R.M., Pan, Y., Je, H.S., Roberts, A.C., Kim, C.J., Berrios, J., Colvin, J.S., Bousquet-Moore, D., Lorenzo, I., Wu, G., Weinberg, R.J., Ehlers, M.D., Philpot, B.D., Beaudet, A.L., Wetsel, W.C., Jiang, Y.H., 2011. Synaptic dysfunction and abnormal behaviors in mice lacking major isoforms of Shank3. Human molecular genetics 20, 3093-3108.

Wecker, J.R., Ison, J.R., Foss, J.A., 1985. Reflex modification as a test for sensory function. Neurobehav Toxicol Teratol 7, 733-738.

Wersinger, S.R., Ginns, E.I., O'Carroll, A.M., Lolait, S.J., Young, W.S., 3rd, 2002. Vasopressin V1b receptor knockout reduces aggressive behavior in male mice. Molecular psychiatry 7, 975-984.

Wise, A., Tenezaca, L., Fernandez, R.W., Schatoff, E., Flores, J., Ueda, A., Zhong, X., Wu, C.F., Simon, A.F., Venkatesh, T., 2015. Drosophila mutants of the autism candidate gene neurobeachin (rugose) exhibit neurodevelopmental disorders, aberrant synaptic properties, altered locomotion, and impaired adult social behavior and activity patterns. J Neurogenet, 1-9.

Witteveen, J.S., Middelman, A., van Hulten, J.A., Martens, G.J., Homberg, J.R., Kolk, S.M., 2013. Lack of serotonin reuptake during brain development alters rostral raphe-prefrontal network formation. Frontiers in cellular neuroscience 7, 143.

Wohr, M., Scattoni, M.L., 2013. Behavioural methods used in rodent models of autism spectrum disorders: current standards and new developments. Behavioural brain research 251, 5-17.

Wohr, M., Silverman, J.L., Scattoni, M.L., Turner, S.M., Harris, M.J., Saxena, R., Crawley, J.N., 2012.

Developmental delays and reduced pup ultrasonic vocalizations but normal sociability in mice lacking the postsynaptic cell adhesion protein neuroligin2. Behavioural brain research.

Won, H., Lee, H.R., Gee, H.Y., Mah, W., Kim, J.I., Lee, J., Ha, S., Chung, C., Jung, E.S., Cho, Y.S., Park, S.G., Lee, J.S., Lee, K., Kim, D., Bae, Y.C., Kaang, B.K., Lee, M.G., Kim, E., 2012. Autistic-like social behaviour in Shank2mutant mice improved by restoring NMDA receptor function. Nature 486, 261-265.

Wooley, C.M., Sher, R.B., Kale, A., Frankel, W.N., Cox, G.A., Seburn, K.L., 2005. Gait analysis detects early changes in transgenic SOD1(G93A) mice. Muscle Nerve 32, 43-50.

Woolfenden, S., Sarkozy, V., Ridley, G., Coory, M., Williams, K., 2012. A systematic review of two outcomes in autism spectrum disorder - epilepsy and mortality. Developmental medicine and child neurology 54, 306-312. 
Wurzman, R., Forcelli, P.A., Griffey, C.J., Kromer, L.F., 2014. Repetitive grooming and sensorimotor abnormalities in an ephrin-A knockout model for Autism Spectrum Disorders. Behavioural brain research 278C, 115-128.

Wyss, J.M., Fisk, G., van Groen, T., 1992. Impaired learning and memory in mature spontaneously hypertensive rats. Brain research 592, 135-140.

Xu, M., Kobets, A., Du, J.C., Lennington, J., Li, L., Banasr, M., Duman, R.S., Vaccarino, F.M., DiLeone, R.J., Pittenger, C., 2015a. Targeted ablation of cholinergic interneurons in the dorsolateral striatum produces behavioral manifestations of Tourette syndrome. Proc Natl Acad Sci U S A 112, 893-898.

Xu, M., Li, L., Ohtsu, H., Pittenger, C., 2015b. Histidine decarboxylase knockout mice, a genetic model of Tourette syndrome, show repetitive grooming after induced fear. Neuroscience letters 595, 50-53.

$\mathrm{Xu}$, Y., Sari, Y., Zhou, F.C., 2004. Selective serotonin reuptake inhibitor disrupts organization of thalamocortical somatosensory barrels during development. Brain research. Developmental brain research 150, 151-161.

Yang, M., Bozdagi, O., Scattoni, M.L., Wohr, M., Roullet, F.I., Katz, A.M., Abrams, D.N., Kalikhman, D., Simon, H., Woldeyohannes, L., Zhang, J.Y., Harris, M.J., Saxena, R., Silverman, J.L., Buxbaum, J.D., Crawley, J.N., 2012. Reduced excitatory neurotransmission and mild autism-relevant phenotypes in adolescent Shank3 null mutant mice. The Journal of neuroscience : the official journal of the Society for Neuroscience 32, 6525-6541. Yang, M., Silverman, J.L., Crawley, J.N., 2011. Automated three-chambered social approach task for mice. Curr Protoc Neurosci Chapter 8, Unit 826.

Yu, D., Mathews, C.A., Scharf, J.M., Neale, B.M., Davis, L.K., Gamazon, E.R., Derks, E.M., Evans, P., Edlund, C.K., Crane, J., Fagerness, J.A., Osiecki, L., Gallagher, P., Gerber, G., Haddad, S., Illmann, C., McGrath, L.M., Mayerfeld, C., Arepalli, S., Barlassina, C., Barr, C.L., Bellodi, L., Benarroch, F., Berrio, G.B., Bienvenu, O.J., Black, D.W., Bloch, M.H., Brentani, H., Bruun, R.D., Budman, C.L., Camarena, B., Campbell, D.D., Cappi, C., Silgado, J.C., Cavallini, M.C., Chavira, D.A., Chouinard, S., Cook, E.H., Cookson, M.R., Coric, V., Cullen, B., Cusi, D., Delorme, R., Denys, D., Dion, Y., Eapen, V., Egberts, K., Falkai, P., Fernandez, T., Fournier, E., Garrido, H., Geller, D., Gilbert, D.L., Girard, S.L., Grabe, H.J., Grados, M.A., Greenberg, B.D., Gross-Tsur, V., Grunblatt, E., Hardy, J., Heiman, G.A., Hemmings, S.M., Herrera, L.D., Hezel, D.M., Hoekstra, P.J., Jankovic, J., Kennedy, J.L., King, R.A., Konkashbaev, A.I., Kremeyer, B., Kurlan, R., Lanzagorta, N., Leboyer, M., Leckman, J.F., Lennertz, L., Liu, C., Lochner, C., Lowe, T.L., Lupoli, S., Macciardi, F., Maier, W., Manunta, P., Marconi, M., McCracken, J.T., Mesa Restrepo, S.C., Moessner, R., Moorjani, P., Morgan, J., Muller, H., Murphy, D.L., Naarden, A.L., Nurmi, E., Ochoa, W.C., Ophoff, R.A., Pakstis, A.J., Pato, M.T., Pato, C.N., Piacentini, J., Pittenger, C., Pollak, Y., Rauch, S.L., Renner, T., Reus, V.I., Richter, M.A., Riddle, M.A., Robertson, M.M., Romero, R., Rosario, M.C., Rosenberg, D., Ruhrmann, S., Sabatti, C., Salvi, E., Sampaio, A.S., Samuels, J., Sandor, P., Service, S.K., Sheppard, B., Singer, H.S., Smit, J.H., Stein, D.J., Strengman, E., Tischfield, J.A., Turiel, M., Valencia Duarte, A.V., Vallada, H., Veenstra-VanderWeele, J., Walitza, S., Wang, Y., Weale, M., Weiss, R., Wendland, J.R., Westenberg, H.G., Shugart, Y.Y., Hounie, A.G., Miguel, E.C., Nicolini, H., Wagner, M., Ruiz-Linares, A., Cath, D.C., McMahon, W., Posthuma, D., Oostra, B.A., Nestadt, G., Rouleau, G.A., Purcell, S., Jenike, M.A., Heutink, P., Hanna, G.L., Conti, D.V., Arnold, P.D., Freimer, N.B., Stewart, S.E., Knowles, J.A., Cox, N.J., Pauls, D.L., 2015. Cross-disorder genome-wide analyses suggest a complex genetic relationship between Tourette's syndrome and OCD. The American journal of psychiatry 172, 82-93.

Zhang, K., Hill, K., Labak, S., Blatt, G.J., Soghomonian, J.J., 2014. Loss of glutamic acid decarboxylase (Gad67) in Gpr88-expressing neurons induces learning and social behavior deficits in mice. Neuroscience 275, 238247.

Zhao, Y., Fung, C., Shin, D., Shin, B.C., Thamotharan, S., Sankar, R., Ehninger, D., Silva, A., Devaskar, S.U., 2010. Neuronal glucose transporter isoform 3 deficient mice demonstrate features of autism spectrum disorders. Molecular psychiatry 15, 286-299.

Zhou, J., Blundell, J., Ogawa, S., Kwon, C.H., Zhang, W., Sinton, C., Powell, C.M., Parada, L.F., 2009. Pharmacological inhibition of mTORC1 suppresses anatomical, cellular, and behavioral abnormalities in neural-specific Pten knock-out mice. J Neurosci 29, 1773-1783. 
Zhuang, X., Oosting, R.S., Jones, S.R., Gainetdinov, R.R., Miller, G.W., Caron, M.G., Hen, R., 2001. Hyperactivity and impaired response habituation in hyperdopaminergic mice. Proceedings of the National Academy of Sciences of the United States of America 98, 1982-1987.

Zikopoulos, B., Barbas, H., 2010. Changes in prefrontal axons may disrupt the network in autism. The Journal of neuroscience : the official journal of the Society for Neuroscience 30, 14595-14609.

Zippelius, H.M., Schleidt, W.M., 1956. Ultraschall-laute bej jungen mausen (Ultrasonic vocalization in infant mice). Die Naturwissenschaften 43, 502-503. 